\title{
SISTEMAS SILVOPASTORALES, ALTERNATIVA DE PRODUCCIÓN INTEGRADA PARA UN DESARROLLO SUSTENTABLE DE LA AGRICULTURA EN CHILE.
}

Álvaro Sotomayor ${ }^{1}$

\section{RESUMEN}

En general el principal interés de los pequeños y medianos productores agrícolas en Chile, dueños de más 8 millones de hectáreas en el país, es proveer de alimento e ingresos para su grupo familiar, por lo que destinan gran parte de su tierra a establecer cultivos anuales o praderas para alimento del ganado (vacunos, caballares, ovinos y caprinos), aunque sea en terrenos de laderas o de aptitud preferentemente forestal. Debido a esto, sus suelos se encuentran erosionados en un $60 \%$.

Estos productores destinan solo un bajo porcentaje a establecer plantaciones forestales que, en promedio en los últimos 5 años, han sido de menos de 2 ha por propietario de un total predial de 50 ha promedio con que cuenta un pequeño agricultor. Por ello, se ha estudiado durante los últimos 6 años un modelo forestal alternativo, destinado a los pequeños productores agrícolas, que considere en su planteamiento la identidad cultural y el sistema de vida de estos productores, la conservación de los recursos naturales y la permanencia de las familias campesinas en el campo, evitando así la migración a la ciudad, como elemento central del desarrollo rural. Para ello se considera la reintroducción de los árboles en la unidad predial campesina bajo un concepto distinto a las plantaciones forestales tradicionales, basado en sistemas agroforestales o agroforestería.

La agroforestería está referida a "Sistemas y tecnologías de uso del suelo y recursos naturales en los cuales las especies leñosas (árboles, arbustos, palmas, etc.) se utilizan deliberadamente bajo un sistema de manejo integral con cultivos agrícolas y/o producción animal, en alguna forma de arreglo espacial o secuencia temporal", los cuales pueden entregar interesantes alternativas económicas (Sotomayor, 1990). Esta forma de reintroducir los árboles en conjunto con la agricultura, ha sido bien recibida por los agricultores, estableciéndose más de 550 ha dentro del proyecto en los últimos 3 años, en terrenos de propiedad campesina, con un promedio de 1,4 ha agroforestal por unidad predial.

En este trabajo se presentan los principales sistemas silvopastorales de uso en Chile por los productores agrícolas, sus usos, resultados y potencialidades de aplicación en el sector silvoagropecuario Chileno, en base a un Programa de Desarrollo Agroforestal conjunto entre el Instituto Forestal (INFOR), el Instituto de Desarrollo Agropecuario (INDAP), el Ministerio de Agricultura y los Gobiernos Regionales y Locales.

Palabras claves: Campesinos, silvopastoral, agroforestería

1-Instituto Forestal de Chile (INFOR), Casilla 109-C, Concepción, Chile. asotomay@infor.cl. 


\section{SILVOPASTORAL SYSTEMS, AN ALTERNATIVE FOR SUSTAINABLE DEVELOPMENT OF THE AGRICULTURE IN CHILE.}

\section{SUMMARY}

The campesinos (small farmers) in Chile, own more than 8 million hectares in rural properties, with an average of 50 hectares. The main objective of the campesinos is to provide food, care and money to cover their first needs. They organize their lands for crops, prairies and livestock production, although the land is mainly forest land, that is eroded, and only a small area is utilized to generate new forest plantations, which in the last five years have been less than two hectares per property. This is one of the reasons why the reforestation activity did not increase in this kind of small owner properties, although in Chile there are more than 2 million hectares without forest cover belonging to campesinos, which can be afforested, even there is a special foment law to promote reforestation in small farmers properties in the country. Other reason is that the extension programs were trying to use the same reforestation strategy that was used in the past with the forest companies and large farming lands, which are not compatible with small farmers, therefore this strategy did not work.

Considering the above, the Forest Institute (INFOR) with the Institute for Agriculture Development (INDAP) studied an alternative model for reintroduce forests in campesino's lands, using the tree in a natural way, with agroforestry arrangement, that allows them to get their main needs through crops, livestock, and wood for energy and timber, but in the same land, in a compatible way altogether with natural resource conservation, land-water-biodiversity, and to promote campesinos to remain in the farm. This new approach has been well received by these producers, which has enabled new land being used in agroforestry systems, such as silvopasture, windbreaks, alley cropping and riparian buffers, with 550 ha established with these systems, during the last three years.

This paper presents the main use of silvopastoral systems in Chile by the farmers, their uses, performance and potential use in Chile, based on a joint effort between the following Chilean institutions: Forest Institute (INFOR), Agriculture Development Institute (INDAP), Ministry of Agriculture, and Regional and Local Governments.

Key words: Small farmers, silvopasture, agroforestry 


\section{INTRODUCCIÓN}

La escasez de alimentos es un problema creciente a nivel mundial, lo cual se hace presente en el mundo rural y en la agricultura campesina en Chile. La presión por la obtención de alimentos se ve limitada por una desigual distribución global de fuentes de alimentos; por procesos de desertificación acelerados por la perdida de cubiertas arbóreas protectoras; por la erosión y la pérdida de suelos por uso de sistemas productivos agrícolas inadecuados a la condición de estos; por la disminución de la superficie boscosa por quemas, sobrepastoreo y roces; por la disminución de suelos fértiles debida a la expansión de las ciudades, la construcción de caminos y otras alteraciones (Sotomayor, 1990a); y por la disminución de la disponibilidad de recursos hídricos.

Tradicionalmente los agricultores han percibido una incompatibilidad entre la producción agrícola y los árboles o bosques presentes en las propiedades rurales. Para ellos los árboles han representado un competidor, estimando que las especies forestales reducen la producción agropecuaria, dado lo cual los árboles y arbustos han sido extraídos o quemados, modificando el paisaje rural a situaciones donde el árbol es escaso y los terrenos están desprotegidos, originando erosión y perdida de fertilidad de los suelos (Figura $\mathrm{N}^{\circ} 1$ ). Cambiar ésta percepción puede ser un proceso lento y difícil, ya que el uso tradicional de la tierra y el escaso manejo o cuidado de los recursos naturales a menudo están firmemente establecidos y socialmente aceptados en las comunidades locales, lo cual requiere un largo proceso de educación y convencimiento con métodos demostrativos y un trabajo participativo con éstas.

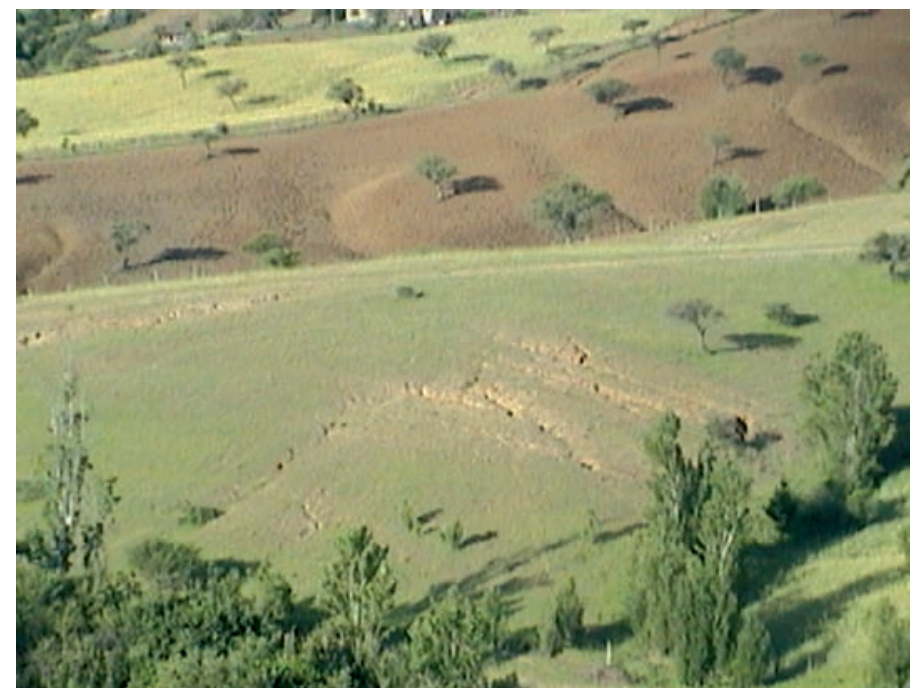

Foto:Carlos Ovalle

Figura $\mathrm{N}^{\circ} 1$

PAISAJE RURAL DEGRADADO POR EXTRACCIÓN DE COBERTURA PROTECTORA EN SUELOS DE LA REGIÓN DEL MAULE 
Una forma de demostrar la compatibilidad de uso de las especies leñosas y la agricultura, es a través del establecimiento de la agroforestería en el mundo rural. El propósito de la inclusión del componente leñoso en conjunto con los usos agropecuarios en un mismo terreno es lograr un sinergismo entre éstos componentes productivos, lo cual puede conducir a mejoras netas en una o más características, tales como productividad y sostenibilidad, así como también a diversos beneficios ambientales y no-comerciales. Como ciencia, la agroforestería es multidisciplinaria y a menudo involucra, o debe involucrar, la participación de campesinos o agricultores en la identificación, diseño y ejecución de las actividades de investigación.

En este documento se exponen los resultados de 8 años de trabajo, donde INFOR e INDAP, con el apoyo del Ministerio de Agricultura, han realizado una labor de difusión y transferencia tecnológica para la implementación de sistemas agroforestales en la agricultura familiar campesina en Chile. La inclusión de los árboles en los sistemas agropecuarios tradicionales de la agricultura no solo puede recuperar el paisaje rural, mejorando su belleza y estética, sino que ayuda a recuperar los suelos y los sistemas hídricos, y a entregar, a través de la introducción de componentes leñosos, una alternativa económica adicional que puede mejorar la rentabilidad del negocio agrícola.

Se presentan los principales sistemas silvopastorales en uso en Chile, desde la Región de Arica y Parinacota, por el Norte, hasta la Región de Aysén, por el Sur.

De acuerdo a los análisis realizados, sobre la base de los resultados obtenidos por el Programa de Desarrollo Agroforestal que el Instituto Forestal lleva a cabo desde al año 2002, y considerando la realidad campesina de Chile, los Sistemas Silvopastorales que mejor interpretan la realidad cultural y las necesidades económicas y ambientales de estos productores, son:

Sistema silvopastoral con tamarugo (Prosopis tamarugo)

Sistema silvopastoral con especies leñosas forrajeras

Sistema silvopastoral con espino (Acacia caven)

Sistema silvopastoral con álamo (Populus spp)

Sistema silvopastoral con pino radiata (Pinus radiata)

Sistema silvopastoral con pino contorta (Pinus contorta)

\section{SISTEMA SILVOPASTORAL CON TAMARUGO}

El tamarugo es una especie nativa y endémica del norte de Chile, particularmente de la "Pampa del Tamarugal", a 70 km al este de la ciudad de lquique, Región de Tarapacá. Este árbol crece en condiciones muy adversas de suelo y clima, es una especie multipropósito y resistente a la sequía. Se la usa como forraje, principalmente por sus brotes tiernos y sus frutos, también como combustible, en usos artesanales, y su madera se aserría para aplicaciones especiales de calidad, como revestimientos de piso.

Crece en el ecosistema desértico de la Pampa del Tamarugal, que presenta características muy particulares. El clima corresponde a un desértico normal, cuyas connotaciones de mayor significancia biológica son: Elevadas temperaturas diurnas, gran oscilación térmica diaria, carencia casi absoluta de precipitaciones, presencia ocasional de neblinas, baja humedad relativa y alta radiación solar (FAO, 1981). Los suelos, constitutitos por material de relleno de origen fluvial, provenientes de la cordillera de Los Andes, están cubiertos por una costra salina 
superficial de 0,10 a 0,60 m o mas de espesor (FAO, 1985; FAO, 1981).

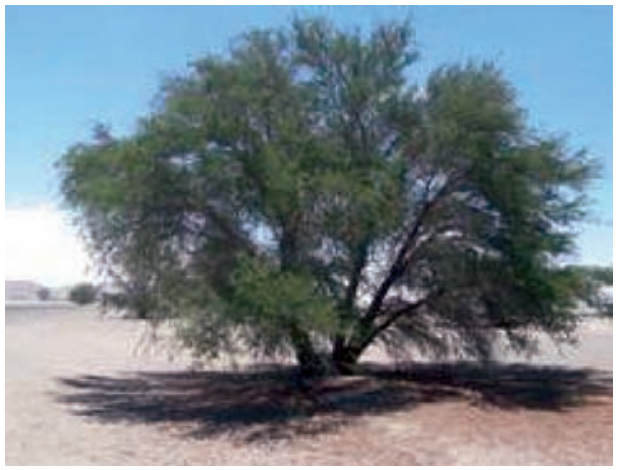

(a)

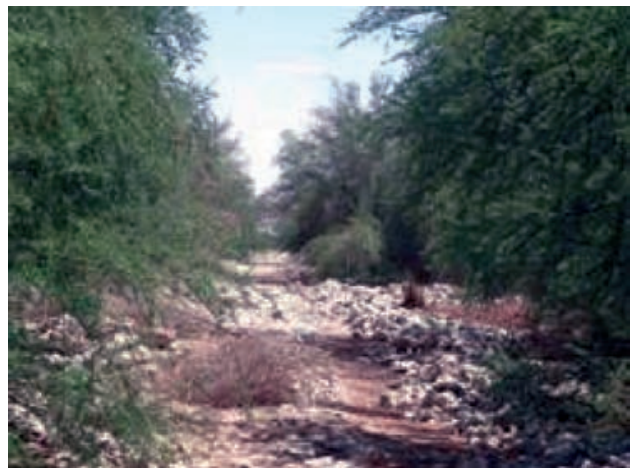

(b)

Figura $\mathrm{N}^{\circ} 2$

ÁRBOL AISLADO DE TAMARUGO (a) Y PLANTACIÓN DE TAMARUGOS (b)

Bajo estas condiciones, en la Pampa del Tamarugal, área protegida bajo la administración de la Corporación Nacional Forestal (CONAF), se realiza un talajeo controlado con caprinos y ovinos en ciertas épocas del año para favorecer a pequeños productores de áreas vecinas a esta área.

El tamarugo produce abundante forraje, utilizado principalmente por el ganado ovino y caprino y, ocasionalmente, por ganado bovino. Su productividad dependerá de su edad y desarrollo, de su densidad, y de la profundidad y calidad del agua de la napa freática. Los frutos y hojas al caer se distribuyen en el suelo, existiendo mayor densidad en la proyección de la copa. El forraje producido contiene $12 \%$ de proteína cruda, $30 \%$ de fibra y 1,9 \% de extracto etéreo, siendo la digestibilidad del fruto para proteína un 13,89\%, para el extracto etéreo 1,16 $\%$, para el extracto libre nitrogenado $28 \%$ y para el total de nutrientes digestibles $50,58 \%$.

Oyarzun (1967) informa que sobre la base de la medición de 19 árboles, obtuvo un peso medio de $2,10 \mathrm{~kg}$ de fruto por metro cuadrado de proyección de la copa de los árboles. Asimismo, en árboles de 30 años de edad, en el promedio de frutos y hojarasca por metro cuadrado de la proyección de la copa de los árboles, observó un rendimiento de $3,40 \mathrm{~kg} / \mathrm{m}^{2}$, de materia seca.

Ensayos de alimentación del ganado ovino (Merino Precoz Francés) en la Pampa del Tamarugal, comparando diferentes dietas, muestran interesantes resultados (Cuadro $N^{\circ} 1$ ). 


\section{Cuadro $\mathrm{N}^{\circ} 1$ \\ RESULTADOS OBTENIDOS CON OVEJAS MERINO PRECOZ FRANCÉS, EN LA PAMPA DEL TAMARUGAL \\ ALIMENTADAS CON HOJAS Y FRUTOS DE TAMARUGO, HENO DE ALFALFA Y ALIMENTACIÓN LIBRE EN BOSQUE}

\begin{tabular}{|l|c|c|c|}
\hline \multirow{2}{*}{ Variables } & \multicolumn{3}{|c|}{ Engorda por Tipo de Alimentación } \\
\cline { 2 - 4 } & $\begin{array}{c}\text { Heno de hojarasca y frutos } \\
\text { de tamarugo (2 kg/día) }\end{array}$ & $\begin{array}{c}\text { Heno de } \\
\text { alfalfa } \\
(1,5 \mathrm{~kg} / \mathrm{día})\end{array}$ & $\begin{array}{c}\text { Utilización libre } \\
\text { en bosque de } \\
\text { tamarugo }\end{array}$ \\
\hline Peso al Destete (kg peso vivo) & 15,0 & 21,5 & \\
Borrega & 14,0 & 25,0 & 26,7 \\
Cordero & 2,81 & 3,18 & 3,77 \\
\hline Peso Vellón (kg) & 5,90 & 6,44 & - \\
\hline Largo de Fibra (mm) & 48 & 63 & 111 \\
\hline Parición (\%) & & & \\
\hline
\end{tabular}

(Lanino, 1966, cit por FAO, 1981)

\section{SISTEMA SILVOPASTORAL CON ESPECIES LEÑOSAS FORRAJERAS}

En Chile este modelo es conocido y relacionado con especies como Atriplex spp y Acacia saligna en la zona semiárida del país, y otras especies que están siendo utilizadas en la zona centro-sur, como es el caso del Chamaecytus proliferus, más conocido como tagasaste.

Las plantas del género Atriplex son especies arbustivas o leñosas bajas, anuales y perennes, de flores unisexuales, las masculinas sin brácteas con envoltura floral y las femeninas con brácteas sin envoltura floral, tienen de uno a cinco estambres unidos en la base y hojas lanceoladas con pelos glandulares y estrellados. Las semillas están envueltas en dos brácteas formando una nuez, dura y difícil de romper en el caso de Atriplex repanda. Los arbustos forrajeros son valorados esencialmente debido a la propiedad de ser fuente de forrajes de ovejas y cabras en períodos secos, cuando no existe otra fuente natural de forraje verde, lo que ocurre durante el período de verano-otoño (Meneses y Squella, 1996). Es así que se han plantado mas de 40.000 ha, principalmente en la Región de Coquimbo para suplementar la escasez de forraje en los meses verano.

Tagasaste es una leguminosa arbustiva siempreverde, capaz de aportar forraje al ganado como suplemento alimenticio en zonas mediterráneas con baja disponibilidad de praderas verdes naturales durante el periodo estival a causa de la sequía (INFOR, 2000). Es una planta leñosa parcialmente resistente a las heladas y a la sequía, muy buena fijadora de nitrógeno y generosa fuente forrajera (Ovalle et al, 1993). Esta especie no se comporta bien en suelos muy arcillosos y con dos o tres días de suelos inundados muere por asfixia radicular. El ideal es un suelo de lomaje suave y de textura liviana. Crece en áreas con precipitaciones entre 500 a $700 \mathrm{~mm}$ anuales y altitudes de 400 a $1.200 \mathrm{msnm}$. La temperatura optima en invierno varía entre $5^{\circ}$ y $15^{\circ} \mathrm{C}$ y entre 20 y $30^{\circ} \mathrm{C}$ en verano. Soporta estaciones secas en verano de 
hasta 4 a 5 meses (Op, cit).

Esta especie puede alcanzar alturas de 2 a 4 m en el secano entre las Regiones O'Higgins y La Araucanía, donde se han obtenido los mejores resultados, en términos de producción de forraje, con valores promedio de 1,8 t/ha/año en la tercera temporada de crecimiento.

En cuanto a su manejo, es necesario realizar control de altura y forma de la copa a través de podas, que permitan por una parte aumentar la disponibilidad de forraje y por otra hacerlo accesible a los animales para ramoneo directo. Ensayos realizados por INIA indican que los mejores resultados, se lograron con podas entre los 80 y $100 \mathrm{~cm}$ de altura. El ramoneo se puede realizar durante el segundo año de establecimiento, realizando pastoreo rotativo por unidades cercadas.

En ovinos, la época de utilización coincide con la época mas critica del año, es decir febrero-marzo durante el encaste, y junio-julio durante la lactancia (Avendaño et al, 1999, en cit por INFOR, 2000).
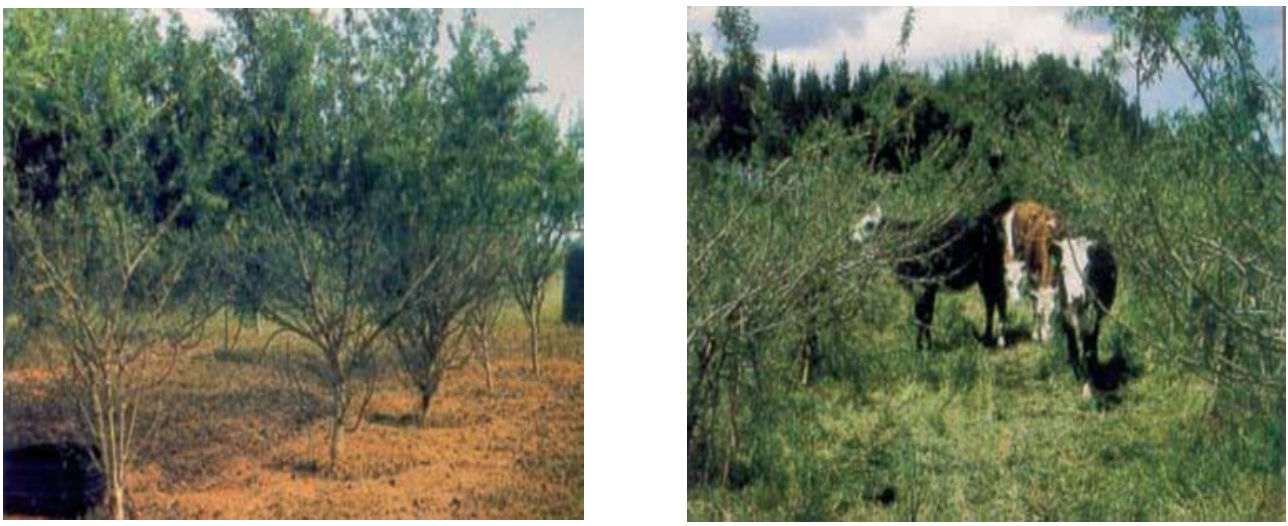

Fotos: Carlos Ovalle

\section{Figura $\mathrm{N}^{\circ} 3$ \\ PASTOREO EN PLANTACIONES DE TAGASASTE}

\section{SISTEMA SILVOPASTORAL CON ESPINO}

Se presentan a continuación para este caso resultados de una experiencia realizada en la Unidad Demostrativa Los Aromos, en la Región del Maule, en el marco del Programa "Modelos Agroforestales para un Desarrollo Sustentable de la Agricultura Campesina en Chile", desarrollado por el Instituto Forestal y financiado por el Instituto de Desarrollo Agropecuario.

Las estepa de Acacia caven (Mol.) Mol, o espinal, cubre una superficie aproximada de 3,8 millones de hectáreas en Chile (FAO, 2008), desde la región de Coquimbo por el norte hasta la Región de Bio Bio por el sur. Puede encontrarse como formaciones puras o asociadas a otras especies arbóreas como quillay (Quillaja saponaria), litre (Lithraea caustica), maitén (Maytenus boaria), y otras. 
Actualmente, la situación de desarrollo de esta especie es producto de la degradación del bosque esclerófilo original, constituyéndose en muchas situaciones como especie dominante, gracias a su capacidad de retoñar desde tocones y raíces. Se encuentra preferentemente en áreas donde la agricultura y ganadería son las actividades productivas más importantes, por lo que ha sido cortada para producir leña y carbón, quemada o rozada para abrir terrenos para la agricultura y ganadería y sobre talajeada por la presión que ejercen los rebaños de ganadería ovina y caprina.

Esta situación podría ser revertida si se hiciera un manejo adecuado de esta especie, especialmente asociada a la ganadería, dado que ha sido demostrado (Olivares, 2006) que con un buen manejo el espino ayuda a un aumento de la productividad de la pradera, tanto natural como artificial.

En este trabajo, se demuestra esta factibilidad, dado que el espino, al ser una especie leguminosa, aporta nitrógeno al suelo, mejora el contenido de materia orgánica (Sotomayor et al. 2008; Olivares, 2006), aumenta la retención de humedad, disminuye e intercepta la radiación solar (Olivares, 2006), y regula la temperatura, especialmente en invierno, con temperaturas superiores bajo copa que fuera del área de proyección (Castillo et al, 1988), lo cual en definitiva mejora las condiciones para el crecimiento y desarrollo de la pradera (Ovalle y Avendaño, 1984).

En el año 2005 se instaló el ensayo en la Unidad Demostrativa Los Aromos con el fin de probar propuestas de manejo de espinales, con pradera natural y sembrada, y compararlas con una pradera natural sin manejo, y evaluar así el efecto del espino en la productividad de la pradera.

\section{Antecedentes Climáticos}

De acuerdo a la clasificación agroclimática de la región, el distrito dominante es Templado Mesotermal Inferior Estenotérmico Mediterráneo Semiárido, presente en cuencas y valles costeros, secano interior (Santibañez y Uribe, 1993).

Las temperaturas oscilan en promedio entre una máxima en enero de $29^{\circ} \mathrm{C}$ y una mínima en julio de $4,9^{\circ} \mathrm{C}$. El período libre heladas es de 259 días, con un promedio de 6 heladas por año. Registra anualmente 1.762 días-grado y 950 horas de frío. La precipitación media anual es de $696 \mathrm{~mm}$, con un déficit hídrico de $931 \mathrm{~mm}$ y un período seco de 7 meses. La menor influencia oceánica favorece la amplitud térmica mayor que los distritos vecinos, con inviernos relativamente fríos y veranos calurosos.

En la zona más oeste existen ciertos cambios en el clima, que se asocian a los identificados para las serranías interiores de la costa. En este caso, las temperaturas varían en promedio entre una máxima en enero de $28,5^{\circ} \mathrm{C}$ y una mínima en julio de $5,4^{\circ} \mathrm{C}$. El período libre de heladas aumenta a 279 días, con un promedio de 2 heladas por año. Registra anualmente 1.712 días-grado y 681 horas de frío. La precipitación media anual es mayor, con $780 \mathrm{~mm}$, el déficit hídrico es de $884 \mathrm{~mm}$ y el período seco se mantiene en 7 meses. Las temperaturas invernales son moderadas, con baja incidencia de heladas y los veranos son calurosos y secos, debido a su cercanía a la costa. 


\section{Material y Método}

Se instalo un ensayo en el predio Los Aromos, a unos $23 \mathrm{~km}$ de la ciudad de Cauquenes, por la ruta a San Javier, en una ladera con exposición noreste, sobre una superficie de 600 $\mathrm{m}^{2}$ de espinal. Este sector, hasta el momento del establecimiento del ensayo, se manejaba bajo un sistema ovino extensivo, con pradera natural, el cual no había sido fertilizado en las 4 temporadas anteriores al ensayo.

Los tratamientos aplicados son los siguientes:

\section{Cuadro $\mathrm{N}^{\circ} 2$}

\section{DESCRIPCIÓN DE TRATAMIENTOS}

\begin{tabular}{|c|l|}
\hline Tratamiento & Descripción \\
\hline A & Silvopastoral espino con pradera sembrada bajo cobertura \\
\hline B & Silvopastoral espino con pradera sembrada con protección lateral \\
\hline C & Silvopastoral espino con pradera natural bajo cobertura \\
\hline D & Silvopastoral espino con pradera natural con protección lateral \\
\hline E & Testigo pradera natural sin protección \\
\hline
\end{tabular}

A. Sistema silvopastoral espino con pradera sembrada bajo cobertura: A través de esta propuesta de esquema de manejo silvopastoral, se pretende demostrar una alternativa de manejo para estos bosques tipo estepa, para mejorar la productividad del suelo. En este caso se manejaron los espinales existentes para lograr una cobertura de copa de entre 40-50\%, con el establecimiento de una pradera establecida con las especies trébol balanza (Trifolium michelianum), hualputra (Medicago polymorpha) y trébol subterraneo (Trifolium subterraneum L. subsp subterraneum), bajo protección de copa del espinal.

B. Sistema silvopastoral espino con pradera sembrada con protección lateral: En este caso se manejaron los espinales existentes con podas y raleos, para lograr una cobertura lateral de alrededor de $30 \%$, con una pradera establecida con las especies trébol balanza (Trifolium michelianum), hualputra (Medicago polymorpha) y trébol subterraneo (Trifolium subterraneum L. subsp subterraneum), bajo protección lateral del espinal.

C. Silvopastoral espino con pradera natural bajo cobertura: En este tratamiento se manejaron los espinales existentes para lograr una cobertura de copa de entre 40-50 \%, con el manejo de la pradera natural existente, con el objetivo de demostrar el efecto de los espinales sobre este tipo de praderas

D. Silvopastoral espino con pradera natural con protección lateral: En este tratamiento de analiza el efecto de la protección lateral de los espinales, con un $30 \%$ de protección, sobre una pradera natural.

E. Testigo pradera natural sin protección: En este tratamiento se evalúa la productividad de una pradera natural sin manejo y sin protección de los espinales, para comparar una situación 
natural de uso de los suelos por parte de pequeños productores agrícolas de esa zona.

En los sistemas silvopastorales con establecimiento de pradera artificial, se realizó poda aérea y de formación a los espinos con objetivos forrajeros y de protección. Para el establecimiento de pradera, se cultivó el suelo para la siembra utilizando los elementos tradicionales del propietario, con caballo, dado que no era posible introducir maquinaria por la presencia de espinos, raíces y tocones. Se realizó rastraje post-siembra y aplicación de fertilizantes (mezcla de superfosfato triple, urea, muriato de potasio, boronatrocalcita y yeso agrícola). A partir del año 2006 fueron introducidos ovinos para su pastoreo.

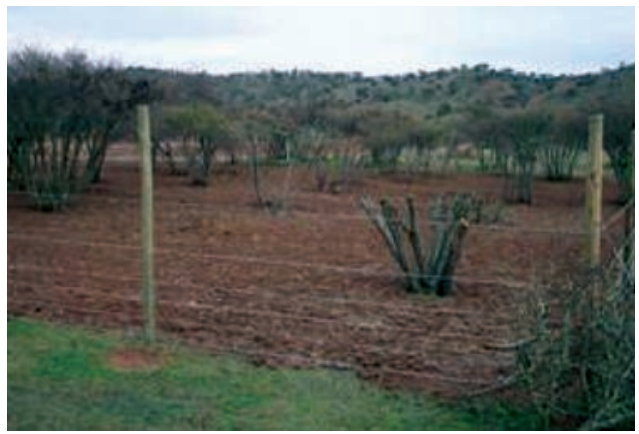

(a) 2005

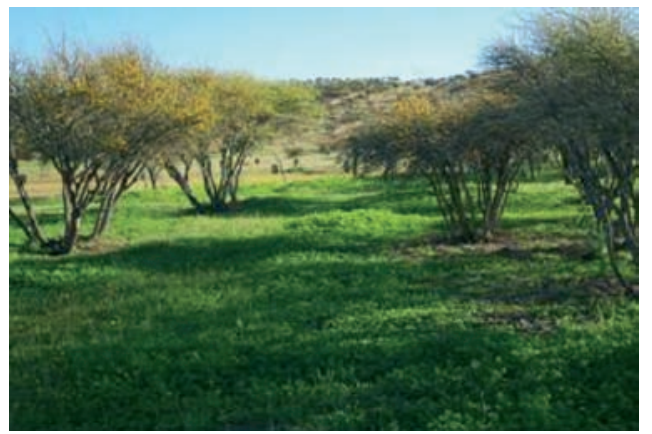

(b) 2006

Figura $N^{\circ} 4$

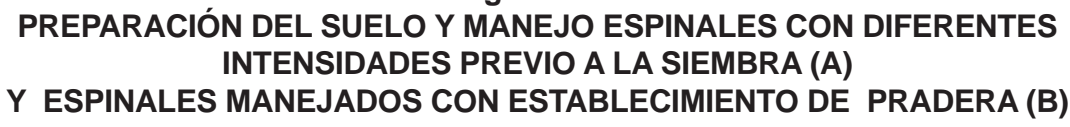

Los espinales fueron podados y raleados para dejar una cobertura de copa de $40-50 \%$ en sectores de tratamiento A y C, y de $30 \%$ para protección lateral en tratamientos B y D; para el tratamiento $\mathrm{E}$, se eligió un sector sin presencia de espinos.

Para la medición de la productividad de la pradera dentro de los tratamientos a evaluar, se miden las variables de la pradera utilizando jaulas metálicas de exclusión, de una medida de $50 \mathrm{~cm}$ de ancho x $100 \mathrm{~cm}$ de largo x $50 \mathrm{~cm}$ de alto, con un área de $0,5 \mathrm{~m}^{2}$. Se utilizaron 3 jaulas de exclusión para cada tratamiento donde se evaluó la productividad de la pradera en materia seca (kg MS ha-1) (Figura $\left.\mathrm{N}^{\circ} 5\right)$.

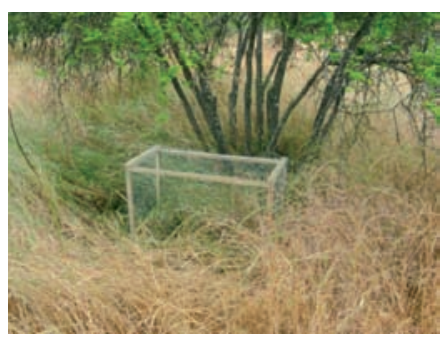

Figura $\mathrm{N}^{\circ} 5$

JAULAS DE EXCLUSIÓN PARA MEDICIÓN DE PRADERA 


\section{Resultados y Discusión}

Los resultados de la evaluación de productividad de la pradera por tratamiento se exponen en el Cuadro $\mathrm{N}^{\circ} 3$.

\section{Cuadro $\mathrm{N}^{\circ} 3$ \\ PRODUCCIÓN DE LA PRADERA POR TRATAMIENTO}

\begin{tabular}{|l|c|c|}
\hline \multirow{2}{*}{ Tratamiento } & \multicolumn{2}{|c|}{$\begin{array}{c}\text { Producción Temporada } \\
\text { (MS kg ha-1) }\end{array}$} \\
\cline { 2 - 3 } & $\mathbf{2 0 0 6 - 2 0 0 7}$ & $\mathbf{2 0 0 7 - 2 0 0 8}$ \\
\hline A. Silvopastoral Espino con Pradera Sembrada Bajo Cobertura & $4467^{\left.\mathrm{a}^{(}\right)}$ & $4050^{\mathrm{a}}$ \\
\hline B. Silvopastoral Espino con Pradera Sembrada con Protección Lateral & $3947^{\mathrm{a}}$ & $4460^{\mathrm{a}}$ \\
\hline C. Silvopastoral Espino con Pradera Natural Bajo Cobertura & $4053^{\mathrm{a}}$ & $3940^{\mathrm{a}}$ \\
\hline D. Silvopastoral Espino con Pradera Natural con Protección Lateral & $2413^{\mathrm{b}}$ & $2410^{\mathrm{b}}$ \\
\hline E. Testigo Pradera Natural sin Protección & $1813^{\mathrm{b}}$ & $1810^{\mathrm{b}}$ \\
\hline
\end{tabular}

$\left(^{*}\right)$ Letras distintas indican diferencias significativas $(p<=0,05)$

De los resultados expuestos se puede inferir el importante efecto de los espinales sobre la productividad de la pradera, dado el efecto protector que reduce la evapotranspiración de los vegetales, aporte de nitrógeno y de materia orgánica. También es importante el aporte sobre la productividad del suelo de una pradera artificial sembrada, especialmente en aquellos casos donde la pradera natural se encuentra muy degradada por efecto de un mal manejo y sobretalajeo, como es en este caso.

La importancia de la cobertura de los espinales en un manejo silvopastoral, se puede deducir si se comparan dos situaciones con pradera natural, con y sin protección de espinales, como es el caso entre el tratamiento $\mathrm{C}$ y $\mathrm{E}$. En este caso el aporte que puede hacer la protección de los espinos implica un aumento de $123,5 \%$ de productividad solo por este efecto. Estos resultados concuerdan con lo expuesto por Olivares (2006) y Ovalle y Avendaño (1984).

También es importante el efecto combinado de la producción de un suelo cuando aparte de manejar adecuadamente la cubierta de espinos, se introduce una pradera artificial para reemplazar una pradera natural altamente degradada. En este caso al comparar los tratamientos $\mathrm{A}$ y $\mathrm{E}$, se observa que por este efecto combinado se puede lograr un aumento de la productividad de un $146,3 \%$.

\section{Conclusiones}

De acuerdo a los resultados expuestos, se concluye que es factible mejorar la productividad de una pradera con fines de producción animal, manejando adecuadamente los espinales.

Este manejo implica mantener una cubierta arbórea que otorgue protección a la pradera, con 
una cobertura de copa entre 40-50 \%, lo cual permitirá mejorara la producción pratense, mejorar la producción animal, y dar protección a los suelos, en especial en aquellas situaciones de laderas donde el sacar la cubierta protectora arbórea origina erosión y pérdida de suelos.

Los espinos, aparte de mejorar la productividad de un sistema silvopastoral, cumplen funciones ecológicas al mejorar las condiciones ambientales bajo su influencia. Entregan protección a los animales frente a bajas y altas temperaturas y pueden ofrecer productos madereros como leña y carbón, y no madereros como hojas y frutos para alimento animal y flores con fines melíferos, junto a mejorar la belleza del paisaje cultural y económico.

\section{SISTEMA SILVOPASTORAL CON ÁLAMOS}

El género Populus tiene especies interesantes para su utilización en sistemas silvopastorales, por su forma de copa y tipo de hoja, lo que permite que la luz penetre más profundamente hacia la pradera que otras especies, coníferas o latifoliadas, de hoja caduca o perenne. Además por ser caduca, permite que en otoño y parte de la primavera la pradera pueda crecer sin grandes interferencias. La principal ventaja de un manejo silvopastoral con esta especie, es que crece en suelos fértiles, con riego, lo cual permite, especialmente en los primeros 7 años de la rotación, que se pueda desarrollar una pradera natural o artificial, mejorada o no, que permitiría sustentar una masa ganadera interesante para los propietarios.

En Chile, la empresa Agrícola y Forestal El Álamo, en la Región del Maule, está utilizando un sistema de producción agropecuario entre las hileras de álamos, con un cultivo de maíz los primeros tres años, para luego pastorear sus plantaciones durante toda la rotación, dado que el sistema permite mantener la pradera y consecuentemente una producción ganadera, aunque a partir del momento del cierre de copas la producción de forraje disminuye.

En el Fundo Austria de Forestal Tornagaleones, en la Región de Los Lagos, INIA desarrolló un estudio silvopastoral con álamo en combinación con diferentes especies forrajeras (Cuadro $\mathrm{N}^{\circ} 4$ ). Esta experiencia de manejo también ha sido usada para recuperación de suelos degradados o improductivos en suelos ñadis. Los pequeños y medianos productores lo utilizan especialmente es suelos de vegas o húmedos, dado que les permite utilizar estos suelos en forma productiva. También se utilizan álamos masivamente en cortinas cortavientos para protección de praderas y cultivos. 


\section{Cuadro $\mathrm{N}^{\circ} 4$ \\ CULTIVOS FORRAJEROS ASOCIADOS A PLANTACIONES DE ÁLAMO}

\begin{tabular}{|l|l|}
\hline Consideraciones técnicas & \multicolumn{2}{|l|}{ Especies/cultivos } & $\begin{array}{l}\text { Especie forestal: Álamo } \\
\text { Especies forrajera estudiadas: Alfalfa, avena, ballica anual, ballica } \\
\text { bianual, ballica híbrida, ballica perenne, cebada, triticale }\end{array}$ \\
\hline Diseño & $\begin{array}{l}\text { Establecimiento cultivos forrajeros en plantaciones de álamo de } \\
\text { edades de 2, 4 y años. } \\
\text { Espaciamiento de plantación } 6 \times 6 \mathrm{~m} . \\
\text { Fecha de siembra: agosto (alfalfa y avena), marzo (ballica anual, } \\
\text { bianual, híbrida y perenne), septiembre (cebada), y mayo (triticate). }\end{array}$ \\
\hline Faenas de establecimiento & $\begin{array}{l}\text { Preparación de suelo tradicional según tipo de cultivo (rastra offset, } \\
\text { vibrocultivador, rodillo compactador, sembradora, etc). } \\
\text { Fertilización. }\end{array}$ \\
\hline $\begin{array}{l}\text { Rotaciones forestal, } \\
\text { agrícola y pecuaria }\end{array}$ & $\begin{array}{l}\text { Forestal: 15 años } \\
\text { Forraje: anual }\end{array}$ \\
\hline $\begin{array}{l}\text { Principales productos } \\
\text { esperados }\end{array}$ & $\begin{array}{l}\text { Forraje y animales. } \\
\text { Materia prima para la industria forestal }\end{array}$ \\
\hline
\end{tabular}

(INIA, 2001)

De las experiencias de INIAen el predio Austria de Forestal Tornagaleones se desprenden los siguientes resultados:

Si bien existieron años en que en los sectores con cultivos no se observaban incrementos en diámetro de los fustes en forma notoria, en general existe un incremento promedio superior en los sectores en los cuales se establecieron alfalfa, ballica bianual, ballica híbrida y cebada $(2,48 \mathrm{~cm}, 2,64 \mathrm{~cm}, 2,51 \mathrm{~cm}$ y, 2,56 cm, respectivamente), comparado con la condición sin cultivo $(2,45 \mathrm{~cm})$.

La fertilización realizada sobre los cultivos mejora el crecimiento de los árboles.

En álamos menores a siete años la producción de materia seca por hectárea de la pradera es interesante, observándose el mejor comportamiento en la ballica y el triticale, posteriormente se reduce significativamente en éstos como en todos los cultivos.

En ballica se obtiene una producción promedio de $8,1 \mathrm{t} \mathrm{ms} / \mathrm{ha}$ con $4 \mathrm{~m}$ de cobertura de copa y $6,2 \mathrm{t} \mathrm{ms} / \mathrm{ha}$ con $5,4 \mathrm{~m}$; en triticale se obtiene 8,7 y $4,1 \mathrm{t} \mathrm{ms} / \mathrm{ha}$ con 5,4 y $6,2 \mathrm{~m}$, respectivamente; en avena se consigue la máxima producción con $4 \mathrm{~m}$ de cobertura y en cebada con 4,4 $\mathrm{m}$ se logran $8,9 \mathrm{t} \mathrm{ms} / \mathrm{ha}$.

Se recomienda establecer las praderas solo hasta que los árboles alcancen una cobertura de copa de 5,4 a 6,2 m.

De acuerdo a la evaluación, la condición para un adecuado crecimiento de los cultivos se logra hasta el séptimo año, alcanzando un $36 \%$ promedio de producción respecto del cultivo tradicional. 
En pradera natural sólo se consigue en promedio $1,96 \mathrm{t} \mathrm{ms} / \mathrm{ha}$ para las mismas coberturas de copas.

Al igual que en la productividad, la calidad del forraje (contenido proteico y energético) y la digestibilidad, disminuyen a medida que aumenta la sombra de los árboles.

El forraje proveniente de cultivos asociados a álamos mayores de seis años presenta problemas en el proceso de fermentación, debido al bajo contenido de carbohidratos solubles y el alto contenido de humedad.
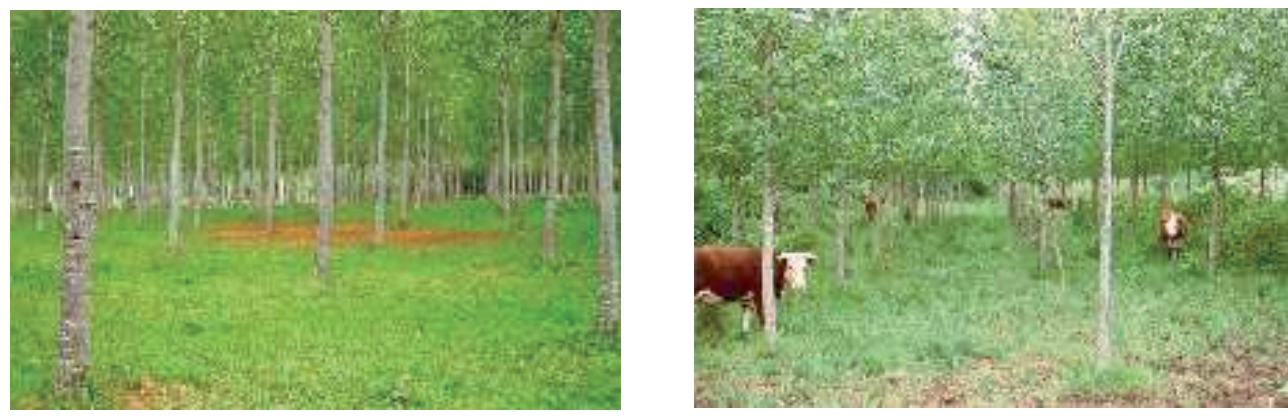

Figura $\mathrm{N}^{\circ} 6$

PRADERAS Y ANIMALES BAJO COBERTURA DE ÁLAMO

En el Cuadro $\mathrm{N}^{\circ} 5$ se exponen algunos resultados de cultivos realizados bajo diversas coberturas de copa con álamos.

\section{Cuadro $\mathrm{N}^{\circ} 5$}

PRODUCCIÓN DE MATERIA SECA DE DIFERENTES CULTIVOS FORRAJEROS EN PLANTACIONES DE ÁLAMO SEGÚN COBERTURA DE COPA, REGIÓN DE LOS RÍOS

\begin{tabular}{|l|c|c|}
\hline \multicolumn{1}{|c|}{ Cultivo Forrajero } & $\begin{array}{c}\text { Cobertura de Copa } \\
\left(\mathbf{m}^{\mathbf{2}}\right)\end{array}$ & $\begin{array}{c}\text { Producción Media Forraje } \\
(\mathbf{t} \text { MS/ha) }\end{array}$ \\
\hline \multirow{2}{*}{ Ballica } & 4,0 & 8,1 \\
& 5,4 & 6,2 \\
\hline \multirow{2}{*}{ Triticale } & 5,4 & 8,7 \\
Avena & 6,2 & 4,1 \\
\hline \multirow{2}{*}{ Cebada } & 4,0 & 6,5 \\
\hline
\end{tabular}

(INIA, 2001) 


\section{SISTEMA SILVOPASTORAL CON PINO RADIATA}

En la actualidad los pequeños propietarios silvoagropecuarios ubicados en el secano costero de la Región de O'Higgins destinan gran parte de sus suelos a la actividad ganadera extensiva, principalmente con ovinos, sin resguardo de la capacidad de uso de los suelos, encontrándose vastas extensiones de suelos de clase VI y VII (forestal-ganadera), cubiertas con praderas naturales de regular a mala calidad, con una baja productividad para la producción de carne y lana, y con suelos erosionados producto de un sobretalajeo y de una baja protección con vegetación perenne sobre estos. Esto radica en que el pastoreo es uno de los rubros que les permite ingresos anuales, junto con cultivos anuales como trigo, cebada, lentejas y otros, tanto para la generación de ingresos para el autoconsumo, como para la venta de productos para la compra de productos de primera necesidad para su grupo familiar.

Por lo anteriormente señalado, el mejoramiento de la rentabilidad de los predios de la Región de O'Higgins, o al menos de un importante segmento de ellos, requiere de innovación y de la incorporación de tecnologías adecuadas, que permitan mejorar la eficiencia de producción de sus rubros tradicionales, y que considere la sustentabilidad del sistema utilizado. Dentro de esta innovación e incorporación de tecnología, es posible la integración del rubro forestal y ganadero en forma conjunta como sistema productivo silvopastoral, dentro de un mismo espacio físico, potrero, o bajo un ordenamiento predial, que permita generar una simbiosis positiva, en la cual se vean beneficiados ambos rubros.

Desde el punto de vista técnico, con la incorporación de árboles en las unidades prediales destinadas a la ganadería tradicional, ordenados de acuerdo a algún diseño silvopastoral, se puede ayudar a incrementar la productividad de los recursos agropecuarios, principalmente en la producción de forraje y producción animal con ganado ovino o bovino, por el mejoramiento de las condiciones ambientales dentro de su área de influencia gracias a la protección brindada por los árboles a los vegetales y animales, que se traduce en disminución de la velocidad del viento, incremento de la temperatura ambiental y del suelo, aumento de la humedad relativa, disminución del déficit hídrico, protección del ganado contra lluvias y bajas temperaturas, entre otros (RAN, 2008; Sotomayor et al., 2004; Sotomayor, 1990; Quam \& Johnson, 1999). Los recursos forestales introducidos son beneficiados por la el ganado en el sistema, a través del control de malezas que afectan el establecimiento y crecimiento de las plantas, en especial en los primeros años de crecimiento; la disminución del riesgo de incendios forestales; el reciclaje de nutrientes en el suelo, las fertilizaciones que reciban las praderas y cultivos forrajeros asociados a las plantaciones; y por el mayor espacio dejado para el crecimiento de los árboles, producto de un ordenamiento agroforestal. Otro aspecto ambiental importante que pueden otorgar los árboles dentro del sistema, es la protección de los suelos frente al viento y las gotas de lluvia, por lo que se espera una disminución de la erosión.

Desde el punto de vista económico, los productores locales que incorporen estas tecnologías mixtas y las integren dentro de sus predios, podrán mantener un flujo de caja anual, dado por la venta de animales (carne y/o lana), que permitirá solventar los gastos propios del grupo familiar, como también del manejo de los bosques mientras estos maduran y entreguen productos (Sotomayor, 1990), y así mejorar su calidad de vida (Leslie et al., 1998; Polla, 1998). Posteriormente, podrán obtener recursos madereros intermedios, como metros ruma, madera para postes o leña, al momento de efectuar las labores de raleos y poda y, finalmente, podrán 
obtener productos maderables de alta calidad (madera libre de nudos o con nudos firmes) al final de la rotación de la plantación forestal al haber manejado sus bosques. Además, sus predios se habrán valorizado al establecer una masa forestal dentro de ellos.

Todo este sistema integrado de producción silvopastoral se caracteriza por su sustentabilidad, ya que permite recuperar terrenos degradados, controlando los procesos de erosión, permitiendo la protección de los cursos de agua y el mejoramiento de la calidad de esta, aumentando la capacidad de captura del $\mathrm{CO}_{2}$ atmosférico y, al mismo tiempo, generar un paisaje estéticamente más agradable y preservar y aumentar la vida silvestre.

Se presentan continuación los resultados de un estudio realizado en el Secano Costero de la Región de O'Higgins, Centro Experimental Forestal Tanumé de la Corporación Nacional Forestal (CONAF), con el objeto de comparar la productividad de sistemas silvopastorales con pino radiata asociados a tres tipos de pradera, con ganado ovino, versus sistemas tradicionales de uso del suelo con ganado ovino, y una situación de manejo forestal tradicional.

\section{Material y Método}

El Centro Tanumé se ubica a $40 \mathrm{~km}$ al norte de la ciudad de Pichilemu, Comuna de Pichilemu, Provincia de Cardenal Caro, $34^{\circ} 15^{\prime}$ LS y $74^{\circ} 49^{\prime}$ LO. Su propietario es CONAF.

La especie forestal utilizada es Pinus radiata. La componente herbácea está representada por praderas sembradas, que incluyen trébol subterráneo (Trifolium subterraneum) y falaris (Phallaris aquatica cv sirosa y cv steptanera); pradera natural mejorada con fertilización; y pradera natural sin fertilización. La componente animal por su parte está constituida por ovinos, de raza Merino Precoz; tipo ovino: borregas secas.

Las principales características climáticas de la zona están dadas por una temperatura media anual de $11,6^{\circ} \mathrm{C}$, una media mínima de $8,6^{\circ} \mathrm{C}$, un período libre de heladas de 9 meses, una precipitación media anual de $705 \mathrm{~mm}$ y un período seco estival de 8 meses. Los suelos se ubican sobre terrazas marinas.

Para evaluar la factibilidad de la combinación silvopastoral en el secano costero de la región el estudio consideró la implementación de diferentes módulos experimentales en los que se comparan los usos tradicionales del suelo en la zona, como son los usos forestales con pino radiata y los usos ganaderos con ovinos, con un sistema silvopastoral con pino radiata asociado a producción ovina y diversos tipos de praderas.

Se instalaron durante el año 1983 unidades de investigación de 6 ha cada una que permitieran estudiar el comportamiento de la especie Pinus radiata bajo densidades silvopastorales (625 $\mathrm{arb}^{-h^{-1}}$ ) y manejo intensivo con ovinos, y su influencia en la productividad de una pradera naturalizada mejorada y una sembrada. Estas se comparan además con un sistema ganadero con ovinos, con los mismos tres tipos de praderas y con un sistema forestal


apropiado para la pequeña propiedad.

El detalle de los tratamientos, su diseño y superficie, se resume en el Cuadro $\mathrm{N}^{\circ} 6$. 


\section{Cuadro $\mathrm{N}^{\circ} 6$ \\ DESCRIPCIÓN DE TRATAMIENTOS A COMPARAR EN TANUMÉ}

\begin{tabular}{|c|c|c|c|c|c|}
\hline \multirow{3}{*}{ Tratamiento } & \multicolumn{3}{|c|}{ Componente Arbóreo } & \multirow{3}{*}{ Tipo de Manejo } & \multirow{3}{*}{ Esquema de Plantación } \\
\hline & \multicolumn{2}{|c|}{$\begin{array}{c}\text { Densidad } \\
\text { (arb/ha }\end{array}$} & \multirow{2}{*}{$\begin{array}{l}\text { Altura } \\
\text { Poda } \\
\text { (m) }\end{array}$} & & \\
\hline & Inicial & Final & & & \\
\hline T 1: PS 625 & 625 & 200 & 7,0 & $\begin{array}{l}\text { Sistema Silvopastoral con } \\
\text { producción ovina, pradera } \\
\text { sembrada de trébol subterráneo y } \\
\text { falaris, asociado con una cubierta } \\
\text { arbórea de Pinus radiata }\end{array}$ & $\begin{array}{l}\text { Plantación en } \\
\text { conglomerados de } 4 \text { plantas } \\
\text { de Pinus radiata plantadas } \\
\text { a } 2 \times 2 \mathrm{~m} \text {, espaciadas a } 6 \mathrm{~m} \\
\text { entre ellos, }(2 \times 2) \times 6 \mathrm{~m}\end{array}$ \\
\hline T 2: PM 625 & 625 & 200 & 7,0 & $\begin{array}{l}\text { Sistema Silvopastoral con } \\
\text { producción ovina, pradera } \\
\text { natural mejorada con régimen } \\
\text { de fertilización, asociado con } \\
\text { una cubierta arbórea de Pinus } \\
\text { radiata }\end{array}$ & $\begin{array}{l}\text { Plantación } \\
\text { conglomerados de } \\
\text { plantas, de Pinus radiata } \\
\text { plantadas a } 2 \text { x } 2 \text { m, } \\
\text { espaciadas a } 6 \text { m entre } \\
\text { ellos, espaciamiento }(2 \times 2) \\
\text { x } 6 \text { m }\end{array}$ \\
\hline T 3: PN 625 & 625 & 200 & 7,0 & $\begin{array}{l}\text { Sistema Silvopastoral con } \\
\text { producción ovina, pradera } \\
\text { natural, asociado conuna cubierta } \\
\text { arbórea de Pinus radiata }\end{array}$ & 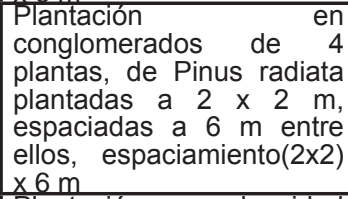 \\
\hline $\begin{array}{l}\text { T4: Forestal } \\
1600\end{array}$ & 1600 & 500 & 4,10 & $\begin{array}{l}\text { Manejo forestal con podas y } \\
\text { raleos con fines de producción de } \\
\text { madera; sin manejo ganadero } \\
\end{array}$ & $\begin{array}{l}\text { Plantación a una densidad } \\
\text { de } 1600 \text { arb/ha, con } \\
\text { espaciamiento a } \\
2 \times 3 \mathrm{~m} \\
\end{array}$ \\
\hline T5: PS & - & - & - & $\begin{array}{l}\text { Sistemaganadero con producción } \\
\text { ovina, y pradera sembrada de } \\
\text { trébol subterráneo y falaris }\end{array}$ & Sin árboles \\
\hline T6: PM & - & - & - & $\begin{array}{l}\text { Sistema ganadero con producción } \\
\text { ovina, y pradera natural mejorada } \\
\text { con fertilización. }\end{array}$ & Sin árboles \\
\hline T7: PN & - & - & & $\begin{array}{l}\text { Sistema ganadero } \\
\text { producción ovina, y y pradera } \\
\text { natural sin fertilización. }\end{array}$ & Sin árboles \\
\hline
\end{tabular}

PS: Pradera sembrada; PM: Pradera Mejorada; PN: Pradera Natural; 625: densidad 625 arb.ha-1; 1600: densidad 1600 arb.ha ${ }^{-1}$. La pradera fue establecida en conjunto con un cultivo de trigo 


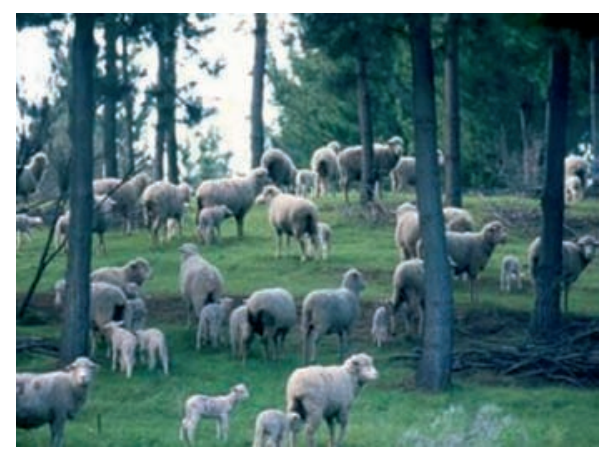

Figura $N^{\circ} 7$

SISTEMA SILVOPASTORAL PINO RADIATA, 18 AÑOS, TANUME

\section{Resultados y Discusión}

Como se indica en la Figura $N^{\circ} 8$, la evolución de los parámetros forestales al momento de la cosecha, es decir a los 24 años, siguen los principios tradicionales de una plantación establecida a bajas densidades versus a altas densidades. En relación al DAP, los mayores diámetros se obtuvieron en los sistemas silvopastorales con diámetros entre los 50 a $52 \mathrm{~cm}$, versus $41 \mathrm{~cm}$ del sistema forestal. El área basal (AB), que es fuertemente influenciada por la densidad, obtuvo los mayores valores con el tratamiento forestal, seguida por T1, que dentro de los sistemas silvopastorales fue el que obtuvo la mayor densidad final con 224 arb ha-1. La altura total, no fue influenciada por la densidad, lo cual indica que los tratamientos fueron instalados en una misma calidad de sitio.

En relación a la productividad del componente forestal, la calidad de los productos que se obtienen de un manejo forestal está directamente relacionada con el material genético utilizado, la calidad del sitio, el manejo, y las densidades utilizadas en la planificación del sistema productivo forestal. Como en este caso el material genético y calidad de plantas fue el mismo y el sitio es uniforme en el lugar, los resultados que se muestran en el Cuadro $\mathrm{N}^{\circ} 7$ son producto del manejo y de la estrategia o diseño utilizado para su establecimiento. La mayor productividad en términos de volumen total se obtuvo en el tratamiento forestal, con $479.5 \mathrm{~m}^{3}$.ha-1, versus una productividad similar entre los tratamientos silvopastorales de $390 \mathrm{~m}^{3}$.ha-1. . La diferencia se produce en cuanto a la calidad de los productos obtenidos y a la distribución de estos productos en la producción total. Los productos podados, que son los que tienen un mayor precio, entregan entre un 37 a $38 \%$ del volumen total en los tratamientos silvopastorales, versus solo un 3,1\% en el sistema forestal. En el sistema forestal el volumen mayor se concentra en P4 y P5, que son productos intermedios en cuanto al valor, lo cual incidirá en la rentabilidad del sistema. 
Figura $\mathrm{N}^{\circ} 8$

RESULTADOS PARÁMETROS FORESTALES A LOS 24 AÑOS

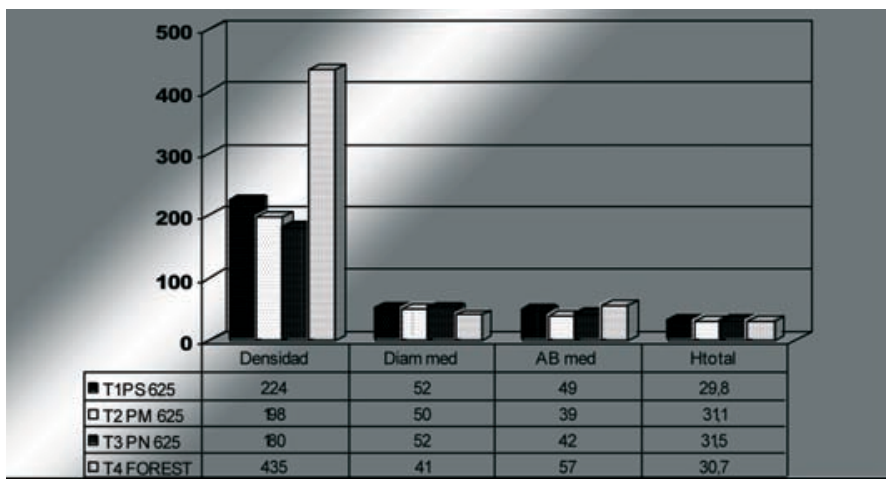

Cuadro $\mathrm{N}^{\circ} 7$

PRODUCCIÓN POR TIPO DE PRODUCTOS AL MOMENTO DE LA COSECHA

\begin{tabular}{|l|r|r|r|r|}
\hline \multirow{2}{*}{ TRATAMIENTOS PRODUCTIVOS } & \multicolumn{2}{|c|}{ CON BONIFICACION } & \multicolumn{2}{c|}{ SIN BONIFICACION } \\
\cline { 2 - 5 } & VAN (10\%) & \multicolumn{1}{c|}{ TIR (\%) } & VAN (10\%) & TIR (\%) \\
\hline T1 Silvopastoral 625-Pradera sembrada & 73,75 & 12,40 & $-10,82$ & 9,70 \\
\hline T2 Silvopastoral 625-Pradera mejorada & 148,38 & 16,20 & 52,81 & 11,50 \\
\hline T3 Silvopastoral 625- Pradera natural & 141,94 & 16,16 & 44,33 & 11,28 \\
\hline T4 Testigo Forestal 1600 & 108,34 & 15,50 & 3,44 & 10,10 \\
\hline T5 Pradera sembrada & $-180,59$ & Indet & $-188,73$ & Indet \\
\hline T6 Pradera mejorada & $-49,26$ & Indet & $-57,55$ & Indet \\
\hline T7 Pradera natural & 0,84 & 10,45 & 0,84 & 10,45 \\
\hline
\end{tabular}

$\mathrm{s} / \mathrm{p}: \sin \mathrm{poda}$

\section{Evaluación Económica}

La evaluación económica de los tratamientos comparados toma en cuenta todos los ingresos, forestales y animales, basado parcialmente en antecedentes de Rodriguez (1998) y Sotomayor y Cabrera (2006), y los incentivos que entrega el Gobierno en base a bonificaciones a la forestación y a la recuperación de suelos, durante toda la rotación de los tratamientos. También toma en cuenta los costos de cada uno de los tratamientos evaluados.

Los resultados que se exponen en el Cuadro $\mathrm{N}^{\circ} 8$, indican que se obtienen los mejores resultados en aquellos tratamientos donde participa la componente forestal, de la especie Pinus radiata. Los mejores resultados en cuanto a VAN y TIR se encontraron en los dos tratamientos silvopastorales T2 y T3, y en el tratamiento forestal T4, sin diferencias significativas entre ellos. Por otro lado, los que obtuvieron la menor rentabilidad fueron los tratamientos ganaderos con ovinos, y en especial aquellos donde participa la componente pradera sembrada, lo cual es similar en el caso silvopastoral. Esto se debe al alto costo de la fertilización que una pradera sembrada con trébol subterráneo y falaris requiere para su desarrollo. 


\section{Cuadro $\mathrm{N}^{\circ} 8$ \\ EVALUACIÓN ECONÓMICA DE LOS TRATAMIENTOS COMPARADOS, CON BONIFICACIÓN Y SIN BONIFICACIÓN FORESTAL}

\begin{tabular}{|l|r|r|r|r|}
\hline \multirow{2}{*}{ TRATAMIENTOS PRODUCTIVOS } & \multicolumn{2}{|c|}{ CON BONIFICACION } & \multicolumn{2}{c|}{ SIN BONIFICACION } \\
\cline { 2 - 5 } & VAN $(10 \%)$ & TIR $(\%)$ & VAN (10\%) & \multicolumn{1}{c|}{ TIR $(\%)$} \\
\hline T1 Silvopastoral 625-Pradera sembrada & 73,75 & 12,40 & $-10,82$ & 9,70 \\
\hline T2 Silvopastoral 625-Pradera mejorada & 148,38 & 16,20 & 52,81 & 11,50 \\
\hline T3 Silvopastoral 625- Pradera natural & 141,94 & 16,16 & 44,33 & 11,28 \\
\hline T4 Testigo Forestal 1600 & 108,34 & 15,50 & 3,44 & 10,10 \\
\hline T5 Pradera sembrada & $-180,59$ & Indet & $-188,73$ & Indet \\
\hline T6 Pradera mejorada & $-49,26$ & Indet & $-57,55$ & Indet \\
\hline T7 Pradera natural & 0,84 & 10,45 & 0,84 & 10,45 \\
\hline
\end{tabular}

\section{Conclusiones}

Los resultados entregados en este estudio, arrojan interesantes resultados en cuanto a la evaluación económica de los tratamientos comparados. Los mejores resultados se obtuvieron cuando participa la componente forestal, con Pinus radiata, es decir sistema silvopastoral y forestal.

Los mejores resultados se obtuvieron en los sistemas silvopastoral con pradera natural manejada (TIR 16,2 \%), silvopastoral con pradera natural (TIR 16,0 \%), y forestal puro (TIR 15,5 $\%)$. Por el contrario, en todos los sistemas ganaderos las rentabilidades fueron negativas.

Los resultados indican que los sistemas silvopastorales son una alternativa para los pequeños propietarios de suelos de secano, dado que son los sistemas mejor evaluados en cuanto a rentabilidad $\mathrm{y}$, además, desde el punto de vista social permiten:

A los propietarios obtener ingresos periódicos producto de cultivos anuales y de la producción animal, en este caso con ovinos, y un interesante ingreso al final de la rotación, por la venta de productos forestales de alta calidad por el manejo de los bosques. En especial en aquellas combinaciones con manejo forestal para madera de alta calidad.

Su aplicación abre la posibilidad de fomento a la forestación con fines diferentes a los que actualmente son incentivados por los programas de forestación del Gobierno, lo cual puede ser de mayor interés para los pequeños propietarios, dado que les permite mantener sus sistemas productivos, adaptándolos más fácilmente con un manejo forestal.

Mayor arraigamiento de los propietarios en sus tierras, evitando la migración a las ciudades, lo cual origina pobreza marginal y cambios de la cultura agrícola.

Beneficios ambientales por la introducción de pinos en los suelos de la cordillera de la 
costa; formaciones graníticas susceptibles de erosión ante un mal manejo agrícola. Los árboles ayudan a recuperar suelos y a restaurar el ambiente degradado por más de un siglo de uso agropecuario eminentemente extractivo.

\section{SISTEMA SILVOPASTORAL CON PINO CONTORTA}

La principal fuente de ingresos de los pequeños y medianos propietarios silvoagropecuarios de la Región de Aysén, Chile, es la actividad ganadera extensiva, basada en terrenos cubiertos con praderas naturalizadas de regular a mala calidad, con una baja productividad para la producción de carne y/o lana, y con suelos erosionados producto del sobretalajeo y la baja protección con vegetación perenne sobre estos. Lo anterior debido a que es el único rubro que les permite ingresos anuales, tanto para la generación de ingresos para el autoconsumo familiar como para el manejo predial.

El mejoramiento de esta realidad en la Región de Aysén requiere innovar e incorporar tecnologías adecuadas en el uso de los recursos naturales, que permitan mejorar la eficiencia de producción de sus rubros tradicionales y que considere la sustentabilidad del sistema utilizado. Dentro de esta innovación e incorporación de tecnología, es posible la integración del rubro forestal y ganadero a través de sistemas silvopastorales dentro de un mismo espacio físico, potrero, o bajo un ordenamiento predial, que permita generar una simbiosis positiva, en la cual se vean beneficiados ambos rubros, forestal y pecuario.

Desde el punto de vista técnico, la incorporación de árboles en las unidades prediales destinadas a la ganadería, ordenados de acuerdo a algún diseño silvopastoral o de cortinas cortavientos, puede contribuir al mejoramiento de la productividad de los recursos agropecuarios, principalmente forraje y ganado bovino u ovino, dado el mejoramiento de las condiciones ambientales por la protección brindada por los árboles, expresadas en una disminución de la velocidad del viento, un aumento de la temperatura ambiental y del suelo, una disminución de la evapotranspiración y protección del suelo y del ganado, entre factores (Sotomayor et al., 2004; Sotomayor, 1990; Quam \& Johnson, 1999; RAN, 2008). Al mismo tiempo, los recursos forestales introducidos se verán beneficiados por la introducción del ganado en el sistema, a través del control de malezas, que pueden afectar el establecimiento y crecimiento de las plantas, en especial en los primeros años de crecimiento; disminución del riesgo de incendios forestales; así como también estarán beneficiados por la fertilización que reciban las praderas asociados a las plantaciones; y el mayor espacio dejado para el crecimiento de los árboles en un ordenamiento agroforestal.

Desde el punto de vista económico, los agricultores que incorporen estas tecnologías en sus predios pueden mejorar el flujo de caja anual por la venta de animales (carne y/o lana) y solventar los gastos propios del grupo familiar, como también del manejo de los árboles mientras estos maduran y entreguen productos (Sotomayor, 1990). De los recursos arbóreos establecidos podrán también obtener productos intermedios, como madera para postes, metros ruma o leña, producto del manejo de la plantación, y podrán obtener productos maderables de alta calidad (madera libre de nudos) al final de la rotación de la plantación forestal al haber manejado sus bosques.

Este sistema integrado de producción silvopastoral se caracteriza por su sustentabilidad, 
ya que permite recuperar terrenos degradados, controlando procesos de erosión, protegiendo cursos de agua y mejorando la calidad de esta, aumentando la capacidad de captura del $\mathrm{CO}_{2}$ atmosférico y generando un paisaje estéticamente más agradable y un aumento de la biodiversidad.

A continuación se exponen los principales resultados de un estudio realizado por el Instituto Forestal (INFOR) y el Instituto Nacional de Investigaciones Agropecuarias (INIA) a partir del año 2003 (Sotomayor et al. 2008), con el objetivo general de incrementar la productividad de los predios de la Región de Aysén, mediante la innovación en el uso de los suelos y de las plantaciones con sistemas de manejo silvopastoral.

\section{Antecedentes de Clima}

El estudio se está desarrollando en el predio San Gabriel, ubicado en la Comuna de Coyhaique, Región de Aysén, Chile, sector Mano Negra, 28 km al norte de la ciudad de Coyhaique, de propiedad de don Víctor Mata, en la Zona Agroecológica Intermedia (Cuadro 9).

Las principales características climáticas de la Región de Aysén están dadas por un volumen de precipitaciones y por vientos de gran intensidad. Sin embargo, esto depende de la ubicación geográfica, existiendo una marcada gradiente geográfica transversal, de acuerdo a la cual la región se puede dividir básicamente en tres zonas agroecológicas (IREN, 1979):

Húmeda: Conformada por el sector de canales y fiordos, mientras que en su porción continental, corresponde a la vertiente occidental de la Cordillera Patagónica.

Intermedia: Se extiende en sentido longitudinal entre Cisne Medio y la cuenca del Lago Cochrane, y desde la vertiente occidental de la Cordillera Andino Patagónica hacia el este, hasta confundirse gradualmente con la Zona de Estepa.

Estepa Fría: Ocupa los sectores adyacentes a la frontera argentina, caracterizada por sus cuencas y amplias mesetas.

Dentro de los fenómenos climáticos regionales, el viento es el que reviste mayor importancia. Según un estudio desarrollado por Mejías et al. (2001), en que analizan el efecto del viento en labores de labranza realizadas en primavera, se ha registrado una pérdida de suelo superior a las 15 t/ha, por acción eólica. Es importante señalar que el $20 \%$ de esta pérdida correspondería a la porción más fértil del suelo, incluyendo nutrientes ( $N, P, K$ y $S$ ) y materia orgánica. 


\section{Cuadro $\mathrm{N}^{\circ} 9$ \\ PARÁMETROS CLIMÁTICOS DE LAS ZONAS AGROECOLÓGICAS DE LA REGIÓN DE AYSÉN}

\begin{tabular}{|c|c|c|c|c|}
\hline \multirow{2}{*}{\multicolumn{2}{|c|}{ Parámetros }} & \multicolumn{3}{|c|}{ Zona Agroclimática } \\
\hline & & Húmeda a & Intermedia ${ }^{b}$ & Estepa $^{c}$ \\
\hline \multicolumn{2}{|c|}{ Superficie aproximada ( Miles ha) } & 1.690 & 600 & 371 \\
\hline \multicolumn{2}{|l|}{$\mathrm{T}^{\circ}$ media $\left({ }^{\circ} \mathrm{C}\right)$} & 9.0 & 7.7 & 6.5 \\
\hline \multicolumn{2}{|c|}{$\mathrm{T}^{\circ}$ media mínima $\left({ }^{\circ} \mathrm{C}\right)$} & 5.7 & 3.9 & 2.2 \\
\hline \multicolumn{2}{|c|}{ Período libre heladas (días) } & 187 & 117 & 39 \\
\hline \multirow{2}{*}{ Viento fuerte (días) } & $>20$ nudos & 6 & 57 & 244 \\
\hline & $>30$ nudos & 0 & 10 & 117 \\
\hline \multicolumn{2}{|c|}{ Precipitaciones $(\mathrm{mm}$ año-1) } & $2.000-4.000$ & $500-1.500$ & $400-700$ \\
\hline \multicolumn{2}{|l|}{ Régimen hídrico } & Superávit todo el año & Déficit estacional + & Déficit estacional ++ \\
\hline \multicolumn{2}{|l|}{ Suelo } & $\begin{array}{l}\text { Delgados } \\
\text { Medianamente } \\
\text { ácidos a ácidos } \\
\text { Textura gruesa }\end{array}$ & $\begin{array}{l}\text { Profundos } \\
\text { Medianamente } \\
\text { ácidos } \\
\text { Livianos }\end{array}$ & $\begin{array}{l}\text { Delgados } \\
\text { Medianamente } \\
\text { ácidos a neutro } \\
\text { Textura gruesa }\end{array}$ \\
\hline
\end{tabular}

La incidencia de vientos fuertes en la Zona Intermedia se produce principalmente entre los meses de diciembre y febrero. En la Zona de Estepa, esta situación es aún más adversa, produciéndose los vientos fuertes en más del $90 \%$ del año, concentrando su mayor intensidad entre los meses de diciembre y febrero.

Una consecuencia relevante de la presencia de este tipo de vientos, es la demanda de humedad del suelo; en las Zonas Intermedia y de Estepa sólo el 15\% de las precipitaciones se produce entre los meses de diciembre y febrero, coincidiendo con la alta incidencia de vientos, y explicando los déficits estacional en los regímenes hídricos producidos en ambas zonas.

\section{Material y Método}

La especie forestal utilizada es Pinus contorta, la pradera es una pradera naturalizada y el ganado es vacuno de razas de carne puras e híbridos.

Para evaluar la factibilidad de la combinación silvopastoral en la Región de Aysén, este estudio consideró la implementación de módulos forestales y silvopastorales sobre plantaciones existentes y no manejadas de Pinus contorta de 12 años de edad, en la localidad de Villa Ortega, sector de Mano Negra, $28 \mathrm{~km}$ al norte de Coyhaique, con el objeto de evaluar y validar bajo las condiciones regionales, algunas alternativas de ordenamiento de las plantaciones y su manejo silvopastoral. Estos módulos se contrastan con un modulo ganadero, bajo un sistema de manejo ganadero tradicional.

Los tratamientos contemplados en los módulos instalados, su diseño y superficie, se describen en el Cuadro $\mathrm{N}^{\circ} 10$ y Figura $\mathrm{N}^{\circ} 9$. 


\section{Cuadro $\mathrm{N}^{\circ} 10$ \\ TRATAMIENTOS EVALUADOS}

\begin{tabular}{|c|c|c|c|}
\hline Tratamiento & Descripción de Tratamientos & $\begin{array}{l}\text { Superficie } \\
\text { Total (ha) } \\
\end{array}$ & $\begin{array}{c}\text { Superficie Efectiva } \\
\text { Pradera (ha) })^{\star \star}\end{array}$ \\
\hline $\mathrm{T} 1$ & Forestal Manejado, 800 arb ha $^{-1}$ & 0,5 & -- \\
\hline $\mathrm{T} 2$ & $\begin{array}{l}\text { Silvopastoral Tradicional con pradera natural, } 400 \\
\text { arb ha }^{-1}\left(\text { Figura } N^{\circ} 9 \text { a) }\right.\end{array}$ & 5,3 & 3,99 \\
\hline T3 & $\begin{array}{l}\text { Silvopastoral en Fajas con pradera natural, } 400 \\
\text { arb ha }^{-1} \text { (Figura } \mathrm{N}^{\circ} 9 \mathrm{~b} \text { ) }\end{array}$ & 5,5 & 4,36 \\
\hline T4 & $\begin{array}{l}\text { Ganadería Tradicional con pradera natural, sin } \\
\text { árboles. }\end{array}$ & 4,3 & 4,30 \\
\hline
\end{tabular}

**: La superficie efectiva de pradera se calculó descontando el área cubierta por desechos de poda y raleo ordenados en fajas.

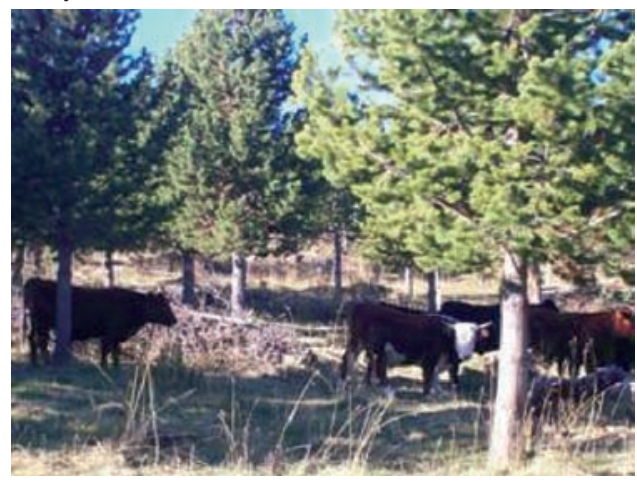

(a)

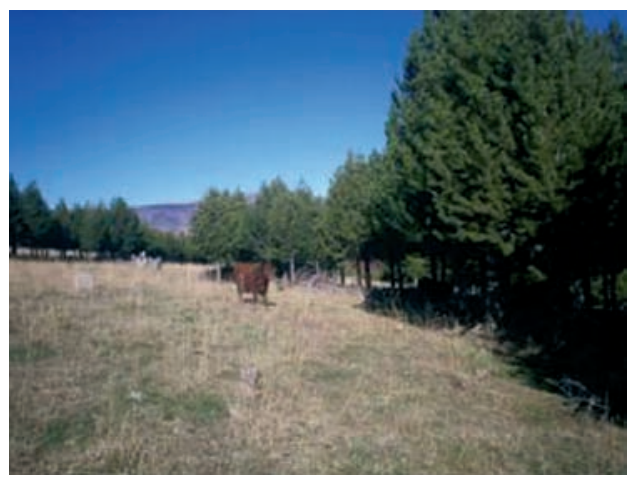

(b)

Figura $\mathrm{N}^{\circ} 9$

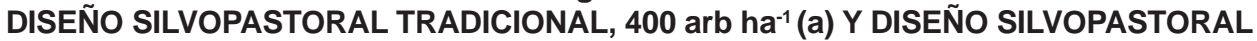

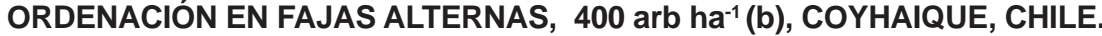

\section{Resultados}

Los resultados de la evaluación de cada uno de los factores productivos se exponen a continuación:

\section{- Productividad y Evolución de la Pradera}

Los resultados de la productividad de la pradera, en materia seca por hectárea, se presentan en el Cuadro $\mathrm{N}^{\circ} 11$. 
Cuadro $\mathrm{N}^{\circ} 11$

PRODUCCIÓN PRADERA TEMPORADA 2004-2005 A 2007-2008

\begin{tabular}{|l|c|c|c|}
\hline \multirow{2}{*}{ Tratamiento } & \multicolumn{3}{|c|}{$\begin{array}{c}\text { Producción Pradera } \\
\left.\text { (kg MS ha }{ }^{-1}\right)\end{array}$} \\
\cline { 2 - 4 } & $\mathbf{2 0 0 4 - 2 0 0 5}$ & $\mathbf{2 0 0 5 - 2 0 0 6}$ & $\mathbf{2 0 0 6 - 2 0 0 7}$ \\
\hline T1: Silvopastoral Tradicional & $1485,7^{\mathrm{b}}$ & $6109,7^{\mathrm{a}}$ & $4153,2^{\mathrm{b}}$ \\
T2: Silvopastoral en Fajas & $2684,9^{\mathrm{a}}$ & $7181,6^{\mathrm{a}}$ & $6394,5^{\mathrm{a}}$ \\
T3: Ganadero Puro & $2452,1^{\mathrm{a}}$ & $3832,0^{\mathrm{b}}$ & $3874,1^{\mathrm{b}}$ \\
\hline
\end{tabular}

Letras diferentes indican diferencias significativas

Se destaca que para todas las fechas evaluadas, en las tres temporadas de evaluación, la producción de la pradera en materia seca por hectárea en el sistema silvopastoral en fajas ha sido la que alcanzó las mayores producciones. El sistema silvopastoral tradicional ha evolucionado positivamente en la segunda y tercera temporada, por sobre el sistema ganadero, debido a un mayor tiempo para el desarrollo de la pradera después de la apertura del dosel superior. Finalmente, en sistema ganadero puro se ha dado el menor desarrollo, muy probablemente por el mal manejo anterior y el efecto del viento que impide el normal desarrollo de la pradera. Estos resultados muestran una tendencia positiva en el desarrollo de la pradera al comparar los sistemas silvopastorales sobre el ganadero puro.

\section{- Productividad y Evolución de la Productividad Animal}

A continuación se expone los resultados de las tres temporadas de medición entre marzo 2005 a mayo del 2007.

\section{Cuadro $\mathrm{N}^{\circ} 12$}

\section{PRODUCCIÓN DE CARNE POR HECTÁREA Y TRATAMIENTO 2004-2007}

\begin{tabular}{|l|c|c|c|}
\hline \multirow{2}{*}{ Tratamiento } & \multicolumn{3}{c|}{ Ganancia en Carne por Hectárea Efectiva de Pradera } \\
\cline { 2 - 4 } & $\mathbf{2 0 0 4 - 2 0 0 5}$ & $\mathbf{2 0 0 5 - 2 0 0 6}$ & $\mathbf{2 0 0 6 - 2 0 0 7}$ \\
\hline & $113,8^{\mathrm{a}}$ & $238,6^{\mathrm{a}}$ & $305,8^{\mathrm{a}}$ \\
\hline T1: Silvopastoral Tradicional & $110,2^{\mathrm{a}}$ & $255,7^{\mathrm{a}}$ & $317,8^{\mathrm{a}}$ \\
T2: Silvopastoral en Fajas & $107,0^{\mathrm{a}}$ & $244,9^{\mathrm{a}}$ & $348,4^{\mathrm{a}}$ \\
\hline
\end{tabular}

Letras iguales indican que no existen diferencias significativas.

La producción total en carne, por hectárea y por tratamiento, en las tres temporadas evaluadas, si bien es levemente superior en el sistema ganadero, no existen diferencias significativas los tratamientos. 


\section{- Productividad y Evolución de los Parámetros Forestales}

Con relación al Diámetro Altura del Pecho (DAP), la evolución del diámetro en los tratamientos con presencia de árboles se observa en el Cuadro $\mathrm{N}^{\circ} 13$.

\section{Cuadro $\mathrm{N}^{\circ} 13$}

DIÁMETRO A LA ALTURA DEL PECHO (DAP) PERIODO 2004-2007

\begin{tabular}{|l|c|c|c|c|}
\hline \multirow{2}{*}{ Tratamiento } & \multicolumn{4}{|c|}{ DAP (cm) } \\
\cline { 2 - 5 } & $\mathbf{2 0 0 4}$ & $\mathbf{2 0 0 5}$ & $\mathbf{2 0 0 6}$ & $\mathbf{2 0 0 7}$ \\
\hline T1: Forest. Manejado & $12,72^{\mathrm{a}}$ & $13,55^{\mathrm{a}}$ & $14,77^{\mathrm{b}}$ & $16,00^{\mathrm{b}}$ \\
\hline T2: Silvop. Tradicional & $12,90^{\mathrm{a}}$ & $14,21^{\mathrm{a}}$ & $15,96^{\mathrm{a}}$ & $17,76^{\mathrm{a}}$ \\
\hline T3: Silvop. Fajas & $12,98^{\mathrm{a}}$ & $14,10^{\mathrm{a}}$ & $15,60^{\mathrm{a}}$ & $17,05^{\mathrm{a}}$ \\
\hline
\end{tabular}

Letras iguales indican que no existen diferencias significativas.

Se puede observar claramente la diferencia de diámetros a la altura del pecho, entre los distintos sistemas forestales ensayados en este proyecto. Al inicio del ensayo en el año 2004 los tratamientos tenían un DAP medio en torno a los $13 \mathrm{~cm}$, pero luego de tres temporadas de crecimiento se evidencia la diferencia por efecto de la densidad entre los sistemas, lo que repercute en aumento de los diámetros en los sistemas con menos árboles por hectárea, es decir los sistemas silvopastorales, con una leve superioridad en el sistema silvopastoral tradicional, $17,76 \mathrm{~cm}$, por tener una menor competencia individual por árbol, en comparación con el sistema en fajas, donde los árboles están concentrados en un menor espacio de crecimiento.

En relación al Área Basal, en el Cuadro N 14 se puede observar su evolución como indicador de ocupación del sitio en los diferentes tratamientos. Está influenciada por el número de árboles de los tratamientos, 400 arb ha $^{-1}$ para los tratamientos silvopastorales y 800 arb ha $^{-1}$ en el tratamiento con manejo forestal, con un mayor valor para el tratamiento forestal. Este parámetro ha tenido un fuerte incremento en los tres tratamientos, aunque con un mayor incremento en los tratamientos silvopastorales, entre un 80 a $90 \%$. Esto indica que en todos los tratamientos o densidades arbóreas existe aún un potencial de crecimiento y que la competencia entre los individuos aún no es muy alta. Con los años se debería esperar que el tratamiento forestal, con más árboles por hectárea, sea el primero en disminuir su crecimiento, por una mayor ocupación del sitio y competencia entre los árboles.

\section{Cuadro $\mathrm{N}^{\circ} 14$ \\ ÁREA BASAL PERIODO 2004 - 2007}

\begin{tabular}{|l|c|c|c|c|c|}
\hline \multirow{2}{*}{ Tratamiento } & \multicolumn{4}{|c|}{$\begin{array}{c}\mathrm{AB} \\
\left(\mathbf{m}^{\mathbf{2}} \mathbf{h a}^{-1}\right)\end{array}$} & $\begin{array}{c}\text { Incremento AB } \\
(\mathbf{\%})\end{array}$ \\
\cline { 2 - 6 } & $\mathbf{2 0 0 4}$ & $\mathbf{2 0 0 5}$ & $\mathbf{2 0 0 6}$ & $\mathbf{2 0 0 7}$ & $\mathbf{2 0 0 4 - 2 0 0 8}$ \\
\hline T1: Forest. Manejado. & $10,55^{\mathrm{a}}$ & $11,96^{\mathrm{a}}$ & $14,20^{\mathrm{a}}$ & $16,64^{\mathrm{a}}$ & 57,7 \\
\hline T2: Silvop. Tradicional & $4,79^{\mathrm{b}}$ & $5,81^{\mathrm{b}}$ & $7,32^{\mathrm{b}}$ & $9,08^{\mathrm{b}}$ & 89,5 \\
\hline T3: Silvop. Fajas & $5,44^{\mathrm{b}}$ & $6,40^{\mathrm{b}}$ & $8,31^{\mathrm{b}}$ & $9,88^{\mathrm{b}}$ & 81,7 \\
\hline
\end{tabular}

Letras iguales indican que no existen diferencias significativas. 
En el caso de la Altura Total $(\mathrm{H})$, dado que los ensayos han sido instalados en un sitio similar, no se observaron diferencias significativas de la altura entre los tratamientos, mostrándose una evolución natural de esta variable en el ensayo (Figura №10).

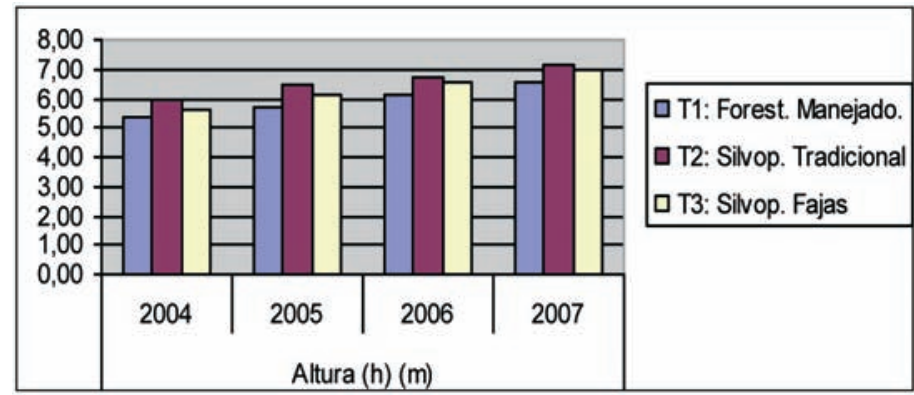

Figura $\mathrm{N}^{\circ} 10$

\section{ALTURA DE LOS ÁRBOLES EN LOS DISTINTOS TRATAMIENTOS PREDIO SAN GABRIEL, PERIODO 2004-2007.}

La cobertura de copa, medida como la proyección de la copa de los árboles sobre el suelo, es una buena variable para relacionar la competencia entre los árboles y la producción de la pradera. En este caso, se observa en el Cuadro $\mathrm{N}^{\circ} 15$, que tanto el sistema forestal manejado como el silvopastoral tradicional han expandido sus copas en forma bastante agresiva, dado que los árboles han tenido suficiente espacio para desarrollar su área foliar. Por el contrario, el sistema en fajas, al estar sus árboles creciendo en un menor espacio y compitiendo fuertemente entre ellos, sus copas se han desarrollado en menor forma.

Cuadro $\mathrm{N}^{\circ} 15$

Cobertura de copa periodo 2004-2007

\begin{tabular}{|c|c|c|c|c|}
\hline \multirow{2}{*}{ Tratamiento } & \multicolumn{3}{|c|}{$\begin{array}{c}\text { Cobertura Copa } \\
(\%)\end{array}$} & \multirow{2}{*}{$\begin{array}{c}\text { Incremento } \\
(\%) \\
2004- \\
2007(\%) \\
\end{array}$} \\
\hline & 2004 & 2006 & 2007 & \\
\hline T1: Forest. Manejado & $26,91^{\mathrm{a}}$ & & $55,13^{a}$ & 104,87 \\
\hline T2:Silvop Tradicional & $14,54^{b}$ & & $28,25^{b}$ & 94,28 \\
\hline T3: Silvop Fajas & $24,19^{a}$ & & $28,88^{b}$ & 19,42 \\
\hline
\end{tabular}

Letras iguales indican que no existen diferencias significativas.

\section{Discusión de los Resultados}

Respecto de la producción de la pradera y producción animal, de acuerdo a los resultados obtenidos en las tres primeras temporadas de evaluación, se ha visto un interesante desarrollo del componente herbáceo en los sistemas con densidades silvopastorales. La producción de la pradera, durante la última temporada, en el tratamiento silvopastoral en fajas fue $2.520,4 \mathrm{~kg}$ MS/ha más alto que el ganadero puro (65 \%) y $2.241,3 \mathrm{~kg} \mathrm{MS} /$ ha más alto que el silvopastoral tradicional (53\%). 
Estos resultados pueden deberse a los beneficios que otorga el componente forestal sobre el entorno que lo rodea, al modificar los factores climáticos; disminuyendo el viento, aumentando la temperatura del suelo y la ambiental y manteniendo una mayor humedad relativa, entre otros factores. Este resultado de la producción pratense, si bien esta relacionado con los resultados obtenidos en la producción animal, no muestra una tendencia tan clara al respecto. La ganancia total en las tres temporadas fue superior en el sistema ganadero (Cuadro $\mathrm{N}^{\circ} 12$ ), pero sin una diferencia significativa, mostrando una tendencia similar en los tres tratamientos. La explicación estaría dada por tres razones:

La productividad de la pradera, medida a través de la producción de kg de materia seca en las jaulas de exclusión y proyectada a la hectárea, indica la productividad teórica del sitio y puede no reflejar fielmente el potencial de producción de la pradera en los distintos tratamientos, producto de la mayor presencia de desechos y árboles en los sistemas silvopastorales.

Una pradera que debe desarrollarse y evolucionar dentro de un sector que estuvo ocupado por una plantación de alta densidad de pinos de 12 años de edad, con más de $90 \%$ de cobertura de copa, presenta una mayor heterogeneidad, producto del efecto ejercido por los árboles antes del manejo (poda y raleo), como también del efecto de los árboles que permanecen dentro del sistema después del manejo. Esto hace difícil interpretar y extrapolar en forma adecuada los resultados obtenidos en las jaulas de exclusión a la productividad total del área de tratamiento, debido a las existencia de muchas condiciones distintas que existen dentro de toda la superficie, situación que no se da tan marcadamente, en una superficie que históricamente ha estado ocupada sólo por pradera (sistema ganadero puro).

Aunque exista una disponibilidad teórica de mayor forraje en los sistemas silvopastorales, esta puede no estar disponible para los animales, producto de la mayor presencia de desechos productos de la poda y el raleo, y por la presencia de árboles en el sistema, lo cual hace mas difícil para los animales el tenerla a disposición.

Otro factor interesante de evaluar es el beneficio directo que tienen los árboles sobre los animales, al otorgarle protección ante bajas y altas temperaturas, y excesivo viento, los que les permite utilizar menos energía para regular su temperatura corporal, lo cual coincide por lo expuesto por Polla (1998), Anderson et al. (1988), y Sotomayor (1990).

En cuanto a la componente forestal, el efecto de un manejo forestal con fines silvopastorales tiene un importante efecto sobre las variables forestales. Por una parte, al disminuir la densidad inicial desde 1.514 a 800 árboles por hectárea en el forestal manejado, y 400 árboles aproximadamente en los diseños silvopastorales, se reduce fuertemente el Área Basal, pero se aumenta el crecimiento en diámetro de los árboles y la producción de la pradera, coincidiendo con lo expuesto por Polla (1998) y Sotomayor (1990). Es decir, se tienen menos árboles pero con un mayor diámetro, lo cual originará en el futuro árboles de mayores dimensiones, obteniéndose una mayor productividad en madera aserrada, o trozos para ser destinados a producción de tableros, por árbol, pero una menor producción de volumen total por hectárea. 
Por otra parte, los tratamientos con una mayor densidad generan un mayor volumen de madera sólida, por lo que estos tratamientos están orientados a producción de biomasa maderera. El sistema forestal manejado, obtendrá un interesante volumen de madera libre de defectos y una mayor proporción de madera con usos industriales de baja calidad, como madera pulpable, leña o postes. Con respecto a la evolución de la copa, se ha visto un fuerte incremento en el tratamiento con mayor número de árboles, forestal manejado, y el silvopastoral tradicional, ya que ambos hasta ahora han tenido suficiente espacio para desarrollarse. Esto debe relacionarse con la producción de la pradera, ya que a un mayor tamaño de copa, existirá una mayor intercepción de la luz, lo cual hará disminuir la producción de la pradera.

\section{Conclusiones}

Después de cuatro años de evaluación y con tres temporadas de mediciones, se observan interesantes resultados que indican la real posibilidad de utilizar sistemas silvopastorales como alternativa productiva y económica para los productores silvoagropecuarios de la Patagonia Chilena, lo cual coincide con los estudios entregados por Universidad Austral de Chile (1988) y Herve et al. (1990).

Estos sistemas, como indican los resultados obtenidos, pueden entregar a los productores:

Producción ganadera: Utilizando el crecimiento de la pradera que crece entre los espacios intercalares o bajo el dosel protector de los sistemas silvopastorales. Esto les permite a los productores obtener anualmente los ingresos necesarios para su grupo familiar.

Producción forestal: La introducción de los árboles en el sistema ganadero tradicional, transformándolo en un sistema silvopastoral, les permite a los propietarios tener otra alternativa productiva, posibilitando una diversificación de la producción predial. A través del manejo se puede obtener madera de dimensiones bajas, para productos como leña, postes, metro ruma y trozos para madera aserrada de dimensiones pequeñas durante el primer sexto de la rotación. Al final de la rotación se obtendrá madera producto de la cosecha, con dimensiones de trozos mayores para productos más nobles como madera aserrada, tablero $u$ otros.

Beneficios ambientales: Junto con el beneficio que se le otorga a la pradera y a los animales, la integración de los árboles también permite mejorar los aspectos ambientales, como reducción de la erosión de los suelos, protección de cursos de aguas, mejoramiento de las condiciones para la vida silvestre presente en la zona y restauración del paisaje afectado por mas de 100 años de colonización.

Producción integrada: Como se observa en los resultados del periodo de evaluación 2004-2007, los sistemas silvopastorales han obtenido ganancias similares en producción de carne, pero adicionalmente obtienen ingresos por madera, lo cual mejora la productividad por unidad de superficie. 


\section{CONCLUSIONES GENERALES PROGRAMA AGROFORESTAL EN CHILE}

El Ministerio de Agricultura de Chile, a través del Instituto Forestal (INFOR), ha desarrollado un Programa de Desarrollo Agroforestal para fomentar la adopción de estas alternativas como una práctica sustentable en predios agrícolas, especialmente en la pequeña propiedad agrícola, y principalmente desde la zona central de Chile (Región de O'Higgins) hasta la Patagonia (Región de Aysén). Durante el periodo del programa se establecieron modelos agroforestales en un total de 558 ha (Cuadro $\mathrm{N}^{\circ} 16$ ).

\section{Cuadro $\mathrm{N}^{\circ} 16$}

\section{MODELOS AGROFORESTALES ESTABLECIDOS POR EL PROGRAMA}

\begin{tabular}{|l|c|c|c|c|}
\hline \multirow{2}{*}{ Modelo Agroforestal } & \multicolumn{3}{c|}{ Año (ha) } & \multirow{2}{*}{$\begin{array}{c}\text { Total } \\
\text { (ha) }\end{array}$} \\
\cline { 2 - 4 } & 2006 & 2007 & 2008 & 43,0 \\
\hline Silvoagrícola & 6,7 & 26,3 & 10,0 & 341,3 \\
\hline Silvopastoral & 162,2 & 112,5 & 66,6 & 145,2 \\
\hline Cortinas Cortavientos & 12,5 & 97,7 & 35,0 & 13,5 \\
\hline Recuperación Riberas & & 3,5 & 10,0 & 15,0 \\
\hline Dendroenergía & & 10,0 & 5,0 & 558,0 \\
\hline TOTAL & 181,4 & 250,0 & 126,6 & \\
\hline
\end{tabular}

Los pequeños propietarios participantes en el proyecto, estuvieron dispuestos a establecer árboles en sus terrenos en alguna forma de arreglo agroforestal, con un promedio de 1,4 ha por propiedad rural, dado que esta alternativa fue menos invasiva y mas cercana a sus tradiciones agrícolas que una forestación tradicional, lo que les permite seguir estableciendo cultivos y criando animales, lo cual a su vez les permite continuar viviendo en sus predios y obtener ingresos y alimentos para su grupo familiar.

El sistema más aceptado fue el silvopastoral, con una superficie establecida de 341,3 ha equivalente a un $61,16 \%$ del total establecido por el programa, principalmente porque los terrenos factibles de establecer árboles en las propiedades rurales de trabajo son situaciones de laderas, sin riego, donde tradicionalmente han manejado praderas naturales de bajo valor productivo, por lo cual es mas fácil transformarlo a una producción silvopastoral. Otro modelo interesante para áreas de cultivos agrícolas, con terrenos más productivos, es el uso de cortinas cortavientos, dado que estos productores reconocen su importancia en el aumento de la productividad de sus cultivos y ganadería.

De los resultados obtenidos en 4 temporadas de trabajo, se puede indicar que los modelos agroforestales, al ofrecer una nueva forma de producción predial integral, representan una interesante alternativa para incentivar a los propietarios de campos agrícolas y ganaderos, y a dueños de plantaciones forestales, a desarrollar estos sistemas mixtos que permiten:

Obtención de ingresos en el corto plazo a través de los animales o cultivos agrícolas.

Valorización de los predios con la incorporación de árboles. 
Recuperación de terrenos degradados, control de la erosión y protección de cuencas.

Obtención de ingresos por productos madereros y no madereros en el mediano plazo, a través de raleos comerciales o utilización directa de productos provenientes del árbol.

Mayor producción de las praderas o cultivos intercalados por efecto de las estructuras arbóreas, como cortinas, que disminuyen la evapotranspiración de los vegetales.

Producción de productos forestales no madereros como miel, frutos y otros.

Protección del ganado en los meses invernales (galpones biológicos), lo que aumenta el porcentaje de pariciones y la sanidad animal.

Mejor calidad de la madera, por proceder de bosques manejados.

Paisaje estéticamente más agradable y aumento de la vida silvestre.

\section{REFERENCIAS}

Anderson, G.W., Moore, R.W. and Jenkins, P.J., 1988. The Integration of Pasture, Livestock and Widely-Spaced Pine in South West Western Australia. Agroforestry Systems, 6: 195-211.

Castillo H, Olivares A, Polzenius G. 1988. Modificaciones de las Características Microambientales Provocadas por la Presencia de Acacia caven (Mol.) Mol. Influencia en el Microambiente. Avances en Producción Animal, 13:31-40, Santiago, Chile.

FAO, 1981. Prosopis tamarugo: Arbusto Forrajero para Zonas Áridas. Oficina Regional de la FAO para América Latina, Santiago, Chile. 143p.

FAO, 1985. Estado Actual del Conocimiento sobre Prosopis tamarugo. Oficina Regional de la FAO para América Latina y el Caribe, Dirección de Producción y Protección Vegetal, Santiago, Chile. 483p.

FAO, 2008. Especies Arbóreas y Arbustivas para las Zonas Áridas y Semiáridas de América Latina: Acacia caven. Red Latinoamericana de Cooperación Técnica en Sistemas Agroforestales. Oficina Regional para América Latina y el Caribe. Santiago de Chile.

Hervé, M., Balocchi, O., Peñaloza, R., 1990. Silvopastoral Sheep and Pine Systems for Small Farmers in Southern Chile. Animal Production. 50(3):192.

INFOR, 2000. Tagasaste, Opción Productiva en Sistemas Silvopastorales para el Secano de la VI, VII y VIII Regiones. Documento de Divulgación N² 21. Instituto Forestal, Santiago, Chile. $12 \mathrm{p}$.

INIA, 2001. Mejoramiento de la Rentabilidad del Álamo a través de Cultivos Asociados. Boletín INIA N 64, Santiago, Chile. 189 p. 
IREN, 1979. Instituto de Recursos Naturales. Caracterización Climática. Perspectivas de Desarrollo de los Recursos de la Región de Aysén del General Carlos Ibáñez del Campo. Intendencia Región de Aysén, Coyhaique, Chile.

Leslie, B., Knowles, R., Moore, R., 1998. Silvopastoreo con Pinus radiata en Zonas Frías. In: Compilación de Resultados en Diversos Ensayos de Modelos Silvopastorales en Chile y en el Extranjero. En el Primer Taller de Manejo Silvícola. Fundación Chile. Santiago, Chile.

Mejias, J., 2001. Estimación de las Pérdidas de Suelo en Sistemas de Labranza Tradicional en la Zona Intermedia de Aysén. In: Explotación Conservacionista de Suelos en Aysén. (Ed.) Instituto de Investigaciones Agropecuarias INIA Tamel Aike. Informe Final. Coyhaique (Chile). $5-15 p$

Meneses, R y Squella, F., 1996. Los Arbustos Forrajeros. In: Ruiz, I. ed. 2da ed. Praderas para Chile. Santiago, INIA. pp 149-170.

Olivares, A., 2006. Relaciones entre el Estrato Arbóreo, el Estrato Herbáceo y la Conducta Animal en el Matorral de Acacia caven (espinal). Science et Changements planétaires/ Sécheresse. Volumen 17, Number 1, 333-9, Janvier-Juin, 2006, Article Scientifique.

Ovalle, C., Avendaño, J., 1984. Utilización Silvopastoral del Espinal. Influencia del Espino, Acacia caven (Mol.), sobre la Productividad de la Pradera Natural. Agricultura Técnica, 44:339345. Santiago, Chile.

Ovalle, C., J. Aronson, H. Alvarez, y J. Avendaño., 1993. Alfalfa Arbórea o Tagasaste (Chamaecytisus proliferus subsp. palmensis), un Árbol Forrajero Leguminoso con Potencial para Sistemas Agrosilvopastorales en Chile Mediterráneo. Agricultura Técnica. (Chile) 53:264271.

Oyarzun, S., 1967. Algunas Variaciones Lanimetricas con Ovejas Merino Encastadas en dos Épocas Diferentes. Canchones. Pampa del Tamarugal. Tesis de Grado. Universidad de Chile, Facultad de Agronomía. Santiago, Chile.

Polla, C., 1998. Estrategias de Acción en el Tema Silvopastoreo. In: Actas Seminario "Manejo Silvopastoral" Trabajo $N^{\circ} 8$, Young. Uruguay.

Quam, V. and Johnson, I., 1999. Windbreaks for Livestock Operations. University of Nebraska Cooperative Extension EC 94-1766-X. Recuperado el 31 de Enero de 2002 de World Wide Web: http:// www. lanr.unl.edu/pubs/forestry/ec1766.htm.

RAN, 2008. Red Agroforestal Nacional, Publicaciones, Cartillas Agroforestales, INFOR, Concepcion, Chile. www.agroforesteria.cl

Rodriguez, M., 1998. Evaluación Económica del Sistema Silvopastoral Pino/Oveja Presente en el Centro Experimental Forestal Tanumé CONAF, VI Región. Memoria Facultad de Ciencias Agrarias y Forestales, Universidad de Chile. Santiago, Chile. 
Santibañez, F. y Uribe, J.M., 1993. Atlas Agroclimático de Chile: Regiones VI y VII. Universidad de Chile, Fac. de Cs. Agrarias y Forestales, Lab. de Agroclimatología. Santiago, Chile. 66 p.

Sotomayor A., Garcia E., Gonzalez, M., 2008. Modelos Agroforestales, Sistema Productivo Integrado para una Agricultura Sustentable. Instituto Forestal, Concepción, Chile. 24p.

Sotomayor, A., 1990a. Sistemas Silvopastorales y su Manejo. Chile Agrícola 157 pp 203206.

Sotomayor, A. 1990. Bosques y Forrajeras pueden Complementarse (II Parte). Chile Agrícola 158:242-248. (No está citado)

Sotomayor, A. y Cabrera, C., 2006. Análisis de un Sistema Silvopastoral con Pinus radiata D. Don, Asociado con Ganado Ovino en la Zona Mediterránea Costera Central de Chile. En: $3^{\text {er }}$ Congreso de Ciencias Forestales, organizado por la Sociedad de Ciencias Forestales de Chile. Concepción, Chile.

Sotomayor, A., Moya, I. y Teuber, O., 2008. Uso de Sistemas Silvopastorales con Pinus contorta (Dougl. ex Loud.), una Realidad Económica para la Patagonia Chilena. En: $4^{\text {to }}$ Congreso Chileno de Ciencias Forestales, Universidad de Talca, 1 al 3 de Octubre de 2008. Editores Dr. Mauricio Ponce Donoso, M.Sc. Marcia Vázquez Sandoval, Talca, Chile.

Universidad Austral de Chile, 1988. Uso Silvopastoral en las Áreas Marginales de la X Región. Valdivia, Chile. 300p. 
SISTEMAS SILVOPASTORALES, ALTERNATIVA DE PRODUCCIÓN INTEGRADA PARA UN DESARROLLO SUSTENTABLE DE LA AGRICULTURA EN CHILE. 